\title{
Spectrally based mapping of riverbed composition
}

\author{
Carl J. Legleiter ${ }^{\mathrm{a}, \mathrm{b}, *}$, Tobin K. Stegman ${ }^{\mathrm{b}}$, Brandon T. Overstreet ${ }^{\mathrm{b}}$ \\ ${ }^{a}$ U.S. Geological Survey, Geomorphology and Sediment Transport Laboratory, Golden, \\ CO, 80403, USA \\ ${ }^{b}$ Department of Geography, University of Wyoming, Laramie, WY 82071, USA
}

\begin{abstract}
Remote sensing methods provide an efficient means of characterizing fluvial systems. This study evaluated the potential to map riverbed composition based on in situ and/or remote measurements of reflectance. Field spectra and substrate photos from the Snake River, Wyoming, USA, were used to identify different sediment facies and degrees of algal development and to quantify their optical characteristics. We hypothesized that accounting for the effects of depth and water column attenuation to isolate the reflectance of the streambed would enhance distinctions among bottom types and facilitate substrate classification. A bottom reflectance retrieval algorithm adapted from coastal research yielded realistic spectra for the 450 to 700 $\mathrm{nm}$ range; but bottom reflectance-based substrate classifications, generated using a random forest technique, were no more accurate than classifications derived from above-water field spectra. Additional hypothesis testing indicated that a combination of reflectance magnitude (brightness) and indices of spectral shape provided the most accurate riverbed classifications. Convolv-
\end{abstract}

${ }^{*}$ Corresponding author. U.S. Geological Survey, Geomorphology and Sediment Transport Laboratory, 4620 Technology Drive, Suite \#400, Golden, CO, 80403, USA; Phone +1 303-271-3651; Email: cj1@usgs.gov (Carl J. Legleiter).

Preprint submitted to Geomorphology

April 4, 2016 
ing field spectra to the response functions of a multispectral satellite and a hyperspectral imaging system did not reduce classification accuracies, implying that high spectral resolution was not essential. Supervised classifications of algal density produced from hyperspectral data and an inferred bottom reflectance image were not highly accurate, but unsupervised classification of the bottom reflectance image revealed distinct spectrally based clusters, suggesting that such an image could provide additional river information. We attribute the failure of bottom reflectance retrieval to yield more reliable substrate maps to a latent correlation between depth and bottom type. Accounting for the effects of depth might have eliminated a key distinction among substrates and thus reduced discriminatory power. Although further, more systematic study across a broader range of fluvial environments is needed to substantiate our initial results, this case study suggests that bed composition in shallow, clear-flowing rivers potentially could be mapped remotely.

Keywords: remote sensing; field spectroscopy; sediment grain size; submerged aquatic vegetation 


\section{Introduction}

Remote sensing has emerged as a powerful tool for characterizing river systems efficiently over large spatial extents (Marcus and Fonstad, 2010). Over the past two decades, a growing number of sensors, ranging from traditional passive optical systems (e.g., Marcus and Fonstad, 2008) to recently developed water-penetrating green LiDARs (e.g., McKean et al., 2008; Kinzel et al., 2013), have enabled a variety of riverine applications (Marcus et al., 2012). Recent examples include large-scale habitat mapping from satellite images (Hugue et al., 2016), identification of refugia from thermal infrared data (Dugdale et al., 2015), and assessment of riverbed stability based on LiDAR-derived topographic information (McKean and Tonina, 2013). Although such studies have demonstrated the potential utility of remote sensing, Legleiter et al. (2016) also identified challenges that must be addressed to scale up from reach-scale feasibility studies to synoptic, watershed-scale mapping. Progress toward this goal is closely linked to the riverscape concept (Carbonneau et al., 2011) and could yield novel insight on fluvial processes. One of the earliest and most common applications of remote sensing to rivers is inferring water depth from passive optical image data (Lyon et al., 1992; Winterbottom and Gilvear, 1997; Gao, 2009). Legleiter et al. (2009) examined the radiative transfer processes involved as solar radiation interacts with stream channels and outlined the conditions under which bathymetric mapping is feasible. When depths are shallow, the water clear, and the streambed relatively bright, bottom-reflected radiance is the dominant component of the signal and accurate depth estimates are possible. Having established the physical basis for spectrally based depth retrieval, this study 
seeks to build upon this framework and infer additional river attributes. More specifically, because the bottom-reflected radiance depends not only on depth but also the reflectance of the streambed itself, spectral information potentially could be used to identify various bottom types. A strong precedent for substrate mapping comes from coastal settings, where remotely sensed data have been used to examine coral reefs and other benthic environments (e.g., Andrefouet et al., 2001; Hochberg et al., 2003; Mobley et al., 2005; Dekker et al., 2011). Here, we adapt this approach to mapping riverbed composition. In fluvial systems, spatially distributed information on the makeup of the channel bed would be useful in geomorphic and ecological contexts. For example, bed material sorting reflects complex interactions among the flow field, the morphology of the channel, and the movement of various grain sizes and often takes the form of distinct, persistent patches with characteristic textures (Lisle et al., 2000; Nelson et al., 2010, 2015). This patchiness implies that even a qualitative, facies-level mapping of spatial patterns of bed material grain size could be highly informative (Buffington and Montgomery, 1999). Although various metrics of image texture have been used to estimate grain size on exposed and/or shallow submerged gravel bar surfaces from very high resolution image data (e.g., Carbonneau et al., 2004; Verdu et al., 2005; Dugdale et al., 2010), we are not aware of any studies that have mapped grain size within the wetted channel on the basis of spectral information.

From an ecological perspective, algae and other types of vegetation anchored on the channel bed form the photosynthetic foundation of lotic ecosystems, converting light to biomass that nourishes higher trophic levels (Giller and Malmqvist, 1998). Substrate-attached algae, known as periphyton, are 
sensitive to particle size (e.g., Cattaneo et al., 1997), flow velocity (e.g., Biggs et al., 1998; Choudhury et al., 2015), and nutrient loading (e.g., Hoyle et al., 2014) and thus serve as an indicator of water quality and general stream health. Benthic algae also influence bed mobility by stabilizing sediment, although mature algal mats can detach from the bed to lift and transport sand and fine gravel even under low-flow conditions (Mendoza-Lera et al., 2016). Periphyton thus have geomorphic as well as ecological significance, and several previous studies have used remote sensing techniques to characterize algae and submerged aquatic vegetation in rivers; Marcus et al. (2012) provide a review. For example, Lee et al. (1999) used field spectra to distinguish among various types of periphyton and macrophytes and to develop regression models for predicting chlorophyll and biomass. Their encouraging results - classification accuracies in excess of $95 \%$ and regression $R^{2}>0.92$ - suggested that benthic vegetation could be mapped from hyperspectral image data. Lee et al. (1999) did not, however, consider the effects of depth or water column optical properties. More recently, Visser et al. (2014) performed object-based analysis of high resolution images and identified depth as an important factor limiting species-level classification of submerged aquatic vegetation. Similarly, Flynn and Chapra (2014) used images acquired from an unmanned aerial vehicle to map a nuisance green algae. Our study extends earlier work by addressing the effects of depth and classifying riverbed composition from field spectra and hyperspectral image data.

Our investigation was founded on the premise that spectrally based substrate mapping could be enhanced by using information on depth and attenuation to account for the influence of the water column and retrieve bottom 
76

77 Maritorena et al. (1994) and Dierssen et al. (2003), to name but two exam78 ples, used this approach to map coral reefs and seagrass, respectively. In 79 this study, we used field spectra measured above the water surface, direct so measurements of water depth, and a parameter summarizing water column 81 attenuation to retrieve bottom reflectance, as illustrated in Fig. 1. The right 82 side of this flow chart outlines how we visually interpreted photos of the 83 streambed to provide training data for a random forest algorithm that ul84 timately produced classifications of sediment facies and algal density. This 85 investigation evaluated the potential for spectrally based mapping of riverbed ${ }_{86}$ composition and primarily used field measurements, but these methods also ${ }_{87}$ were applied to a hyperspectral image to assess the feasibility of identifying 88 bottom types remotely. 


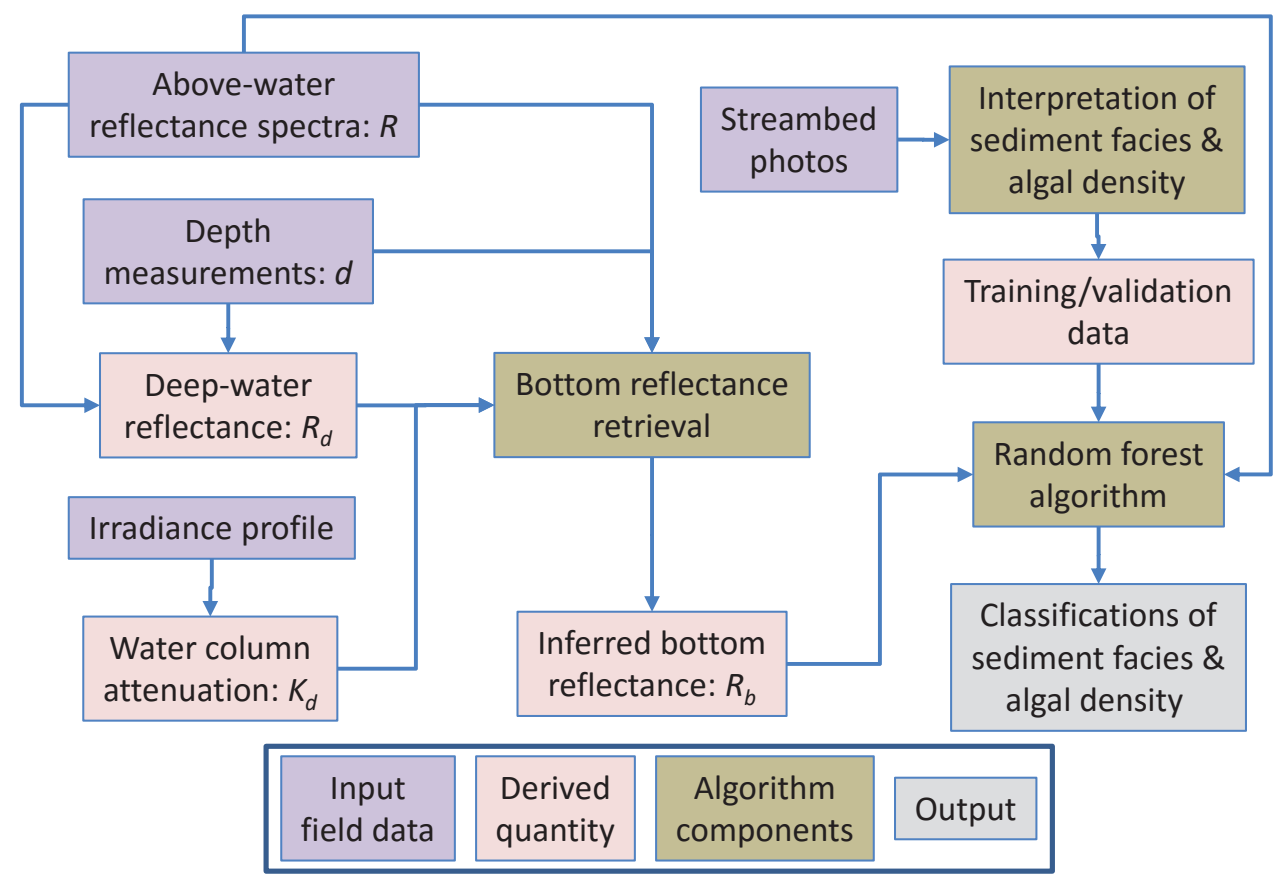

Fig. 1. Flow chart for retrieving bottom reflectance from above-water field spectra or remotely sensed data and using this information to delineate various bottom types.

Our primary research objective was to establish a framework for mapping the substrate of relatively shallow, clear-flowing rivers amenable to remote sensing. More specifically, we used field spectra to determine the extent to which disparate sediment facies and different levels of algal development could be delineated based on above-water measurements and/or retrieved bottom reflectances. Several research questions motivated this inquiry:

- Can different grain size categories be distinguished from one another: sand, gravel, cobble, and various mixtures thereof?

- Similarly, can patches of high algal density be distinguished from areas with lesser amounts of submerged aquatic vegetation? 
- Can these distinctions be made from reflectance spectra collected in the field from above the water surface?

- Does accounting for the effect of the water column to retrieve bottom reflectance enhance these distinctions and facilitate substrate mapping?

- Which variables - reflectance magnitudes or indices of spectral shape — are most informative in distinguishing among various bottom types?

- Do multispectral satellites and hyperspectral imaging systems provide sufficient spectral resolution to support streambed mapping?

\section{Methods}

\subsection{Study area and field data collection}

To evaluate the potential for spectrally based mapping of riverbed composition, we collected field data along the Snake River within Grand Teton National Park WY. This site was the subject of several channel change studies (Marston et al., 2005; Erwin et al., 2011; Nelson et al., 2013) and previous efforts to develop remote sensing methods (Legleiter and Overstreet, 2012; Legleiter, 2013, 2015; Legleiter et al., 2016). Location maps and descriptions of the study area are available in these publications. The present investigation was based on field observations of depth, reflectance, and bottom type collected between Swallow Bend and Deadman's Bar on 17 August 2012. In addition, an image of Rusty Bend was used to illustrate how this approach to riverbed mapping might be applied to remotely sensed data.

Whereas prior work along the Snake emphasized spectrally based depth retrieval, herein we focused on the river's bed, which is composed primarily of gravel to cobble-sized material, with lesser amounts of sand. We did not 
attempt to infer absolute particle sizes but rather adopted a facies-level classification of sediment grain size distributions (Buffington and Montgomery, 1999). The substrate tends to be coated with varying degrees of periphyton and macrophytes, filamentous algae, and other forms of submerged aquatic vegetation that occur in irregular patches. Species-level classification was beyond the scope of this study so we referred to all photosynthetic organisms attached to the bed as algae and distinguished various algal densities.

Field data were collected from a specially designed research cataraft that served as a mobile, highly maneuverable platform for deploying the following instrumentation: Trimble R8 real-time kinematic (RTK) and ProXH differential GPS receivers, used to establish the locations of all measurements; a Seafloor Systems Hydrolite-TM echo sounder for recording water depths with an accuracy of $1 \mathrm{~cm} / 0.1 \%$ of depth; an Analytical Spectral Devices (ASD) FieldSpec3 spectroradiometer for measuring spectra; and a GoPro camera encased in a waterproof housing for photographing the riverbed. Simultaneous, georeferenced observations of depth, reflectance, and bottom composition were obtained while traveling along the river. We sampled a series of transects at Swallow Bend, including a deep backwater with a sand substrate and patches of dense aquatic vegetation, and then made a single downstream pass through the remainder of the study area. Water column optical properties were clear and homogeneous throughout this river segment.

Field spectra were measured above the water surface using a fore-optic mounted on a spar projecting from the rear of the cataraft and connected to the ASD with a waterproof fiber optic cable. This configuration allowed us to avoid self-shading effects and ensured that the water surface was not affected 
by wake from the cataraft. The fore-optic had a $7.5^{\circ}$ field of view and was typically $0.25 \mathrm{~m}$ above the water surface, implying a $0.0034 \mathrm{~m}^{2}$ measurement area at the water surface and $0.085 \mathrm{~m}^{2}$ of the bed for a typical depth of $1 \mathrm{~m}$. Spectra were recorded in reflectance mode by first measuring the instrument response when viewing a Spectralon white reference panel and then dividing subsequent readings by this standard. Every 10 to 15 minutes we optimized and calibrated the ASD by extending the Spectralon panel along the spar into the sensor's field of view. By default, the ASD averages 10 individual spectra recorded at a sampling frequency set by the integration time to obtain a single output spectrum saved to the computer controlling the instrument. However, because the cataraft was moving while these measurements were being made, we did not perform any averaging and recorded individual spectra once each second. This protocol avoided aggregating spectra collected above variable bottom types. The spectral sampling interval of the ASD was $1 \mathrm{~nm}$ over the range from 350 to $1025 \mathrm{~nm}$, with a 3-nm full-width half maximum.

To link these observations of the river's spectral characteristics to bottom composition, we used a downward-facing camera to obtain photos of the streambed beneath the cataraft at the same sampling frequency as the field spectra. For a typical distance above the bed of $1 \mathrm{~m}$, the GoPro camera's effective focal length and detector array dimensions translated into a pixel size of $0.56 \mathrm{~mm}$ and an image extent of $1.61 \times 2.15 \mathrm{~m}$. Each substrate photo thus encompassed an area substantially larger than the footprint of an individual field spectrum. The camera's fisheye lens produced some distortion along the margins of each photo, but we did not attempt quantitative digital grain size analysis (e.g., Buscombe, 2013); these effects did not preclude 
qualitative, visual interpretation of sediment facies and algal density.

In addition to the reflectance spectra, we also used the ASD to characterize attenuation of light within the water column (Legleiter et al., 2016). Briefly, we measured a vertical profile of downwelling spectral irradiance by mounting an upward-facing fore-optic with a cosine response on the end of a measurement crane that allowed us to lower the sensor to various positions within the water column. A pressure sensor adjacent to the fore-optic was used to define the depth of each measurement.

\subsection{Field data processing}

Because the ASD, camera, and echo sounder were mounted on the cataraft in different positions, georeferencing the data required additional processing. We used simultaneous positions from the two GPS receivers to determine the location and orientation of the cataraft and then calculated the coordinates of each measurement based on the sensor-mounting geometry relative to the GPS receivers. Having established the locations of each measurement, we interpolated depth measurements from the echo sounder to estimate the depth of each spectrum and photo; kriging was used within Swallow Bend, where data density was highest, and linear interpolation for the remainder of the study area. We linked reflectance to bottom composition by pairing each field spectrum with the nearest photo.

Processing field spectra involved truncating the data to 400 to $900 \mathrm{~nm}$ and then smoothing each spectrum by twice applying a cubic Savitzky-Golay (Savitzky and Golay, 1964) filter with a 15-nm frame width. In addition to meaningful differences in reflectance driven by variations in depth and bottom type, several types of noise affected the field spectra. For example, reflectance 
tended to drift between observations of the Spectralon panel because of motion of the sun through the sky, even though atmospheric conditions were clear and consistent throughout our measurement period. Another, more variable factor was sun glint from the water surface, which depends on viewing and illumination geometry and can fluctuate from one second to the next caused by differences in water surface roughness (Mobley, 1999). Although various methods for removing sun glint from optical image data have been applied in coastal environments (Hedley et al., 2005; Kay et al., 2009; Martin et al., 2016), none of these techniques are directly applicable to field spectra from rivers. Instead, we used a simpler approach specifically intended to remove the effects of variable surface reflectance on above-water field measurements (O’Neill et al., 2011). Owing to strong absorption of near-infrared (NIR) light by water, water-leaving radiance at wavelengths greater than $850 \mathrm{~nm}$ is negligible and any measured radiance can be attributed to surface reflectance. To account for these effects, we standardized each of our field spectra by calculating the mean reflectance from 850 to $900 \mathrm{~nm}$ and subtracting this value across the spectrum:

$$
R^{\prime}(\lambda)=R(\lambda)-\overline{R(850-900)}
$$

where $R(\lambda)$ and $R^{\prime}(\lambda)$ are the original and standardized reflectances, respectively, at each wavelength $\lambda$ and the overbar indicates an average over the indicated range of wavelengths. This procedure provided a more internally consistent, less noisy reflectance data set (Fig. 2) and the resulting NIRstandardized reflectance spectra $R^{\prime}(\lambda)$ were used for all subsequent analyses.

To characterize bed composition, the closest GoPro photo to each of the 3377 field spectra was visually inspected by a single, trained operator. This 

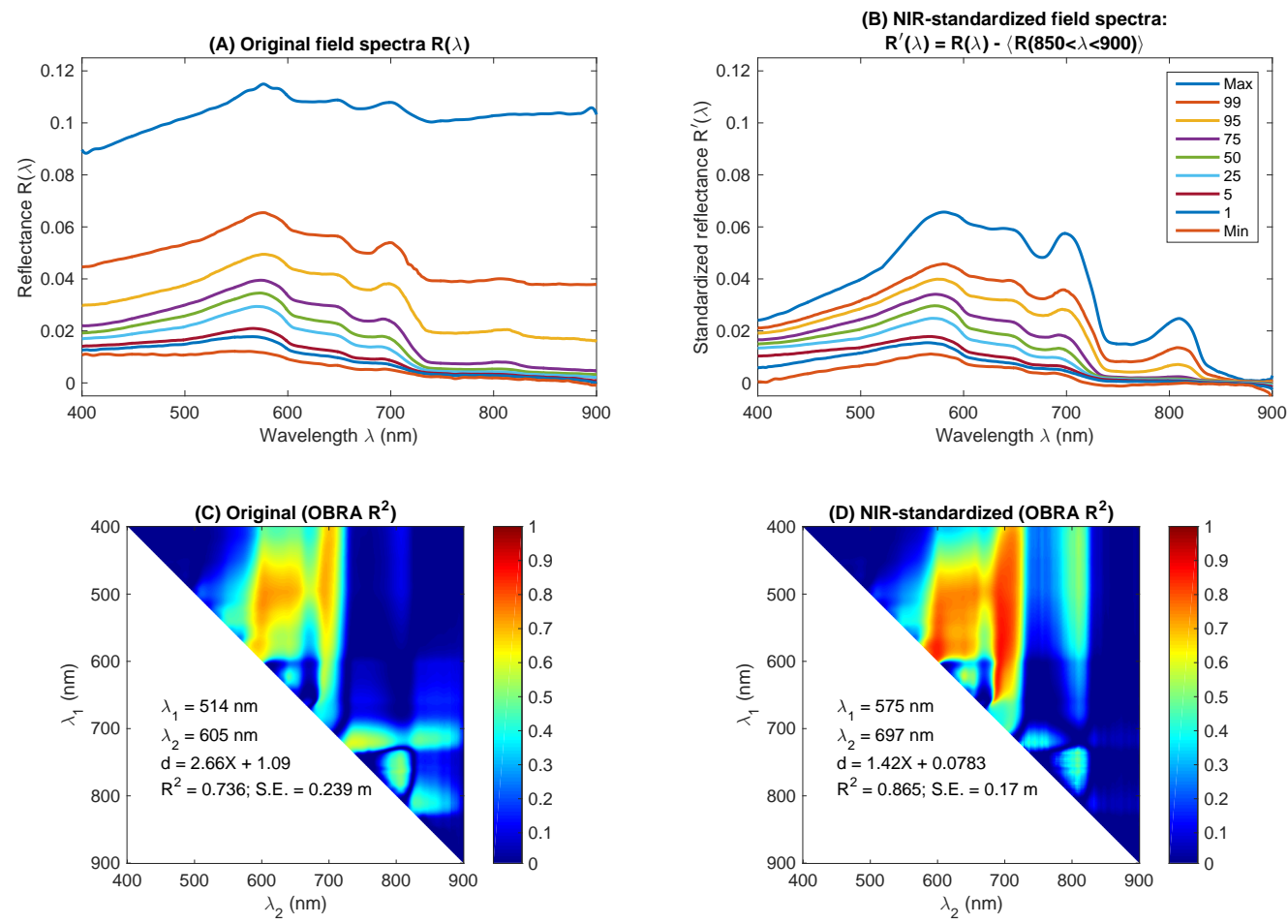

Fig. 2. (A) Original and (B) near-infrared standardized field spectra. Numbers in the legend refer to percentiles of the reflectance distributions $(n=3377)$. Optimal band ratio analysis (OBRA) of the (C) original and (D) standardized field spectra. 
analysis was performed using a custom interface that indicated the location of each photo/spectrum on a background image. A scale bar was added to each photo based on the local flow depth, camera focal length, and pixel size of the detector array. Each photo was assigned to one of seven sediment textural facies (sand, sand/gravel, sand/gravel/cobble, sand/cobble, gravel, gravel/cobble, or cobble) and given an ordinal ranking of algal density from 1 (low) to 5 (high). The original categorizations also were aggregated to a set of three facies (sand, gravel/mixture, and cobble) and low (rank 1), medium (2 and 3), and high (4 and 5) algal densities. Though this approach was subjective, more automated procedures of analyzing the photos proved to be no more practical and far less reliable. Similar, visually based classifications of substrate images have been employed in coastal research (e.g., Fearns et al., 2011; Vahtmae and Kutser, 2013; Reshitnyk et al., 2014; Roelfsema et al., 2015) and are accepted as a robust approach to delineating bottom types more complex and variable than those encountered in this fluvial environment.

Pairing the field spectra to the classified streambed photos allowed us to associate each reflectance measurement with a particular sediment facies and algal density ranking. We summarized these data by calculating the mean and standard deviation of $R^{\prime}(\lambda)$ for each facies and algal density, for the original and for the aggregated categorizations. In addition to bed composition, variations in water depth $d$ influenced $R^{\prime}(\lambda)$ and could affect our ability to distinguish bottom types. To account for this possibility, we used box plots and analysis of variance (ANOVA) to assess whether the various sediment facies and algal densities had significantly different distributions of 
depth $(p<0.05)$.

To account for water optical properties in retrieving bottom reflectance from above-water field spectra and/or remotely sensed data, we used paired observations of depth and downwelling spectral irradiance from a vertical profile measured at Swallow Bend to calculate a diffuse attenuation coefficient, $K_{d}(\lambda)$ (Mishra et al., 2005). This apparent optical property summarized absorption and scattering of light within the water column and thus provided a critical, site-specific input to subsequent calculations of bottom reflectance.

\subsection{Spectral analysis and variable selection}

Our field spectra were essentially continuous, with 500 bands spaced every $\mathrm{nm}$ from 400 to $900 \mathrm{~nm}$, but applying classification algorithms to such high resolution data was impractical. The spectra also were statistically redundant because of the smooth, gradual variation of reflectance with wavelength. Our analysis thus involved an initial phase of data reduction and variable selection that closely followed O'Neill et al. (2011). First, we evaluated whether NIR-standardization (Eq. 1) mitigated the noise associated with our raw field measurements by performing optimal band ratio analysis of the original and standardized spectra. Optimal band ratio analysis (OBRA) is an established depth retrieval technique that identifies the band combination that yields the strongest correlation between the spectrally based quantity $X=\ln \left[R\left(\lambda_{1}\right) / R\left(\lambda_{2}\right)\right]$ and depth $d$ (Legleiter et al., 2009). Because depth is the primary control on reflectance in shallow, clear-flowing rivers such as the Snake, comparing OBRA results from the original and standardized spectra served as a means of assessing the extent to which NIR-standardization improved the signal-to-noise characteristics of our field spectra. 
Two methods were applied to the standardized field spectra to guide selection of a reduced number of spectral quantities for distinguishing among facies and algal densities. First, we quantified class separability by calculating $M$ statistics for all class combinations and all wavelengths. The $M$ statistic normalizes the difference between two class means by the sum of their standard deviations, with high values of $M>1$ for a particular class combination at a given wavelength indicating clear separation between the two classes (Kaufman and Remer, 1994). The second method involved visually inspecting spectra to locate reflectance peaks and valleys that appeared capable of discriminating among substrates, followed by derivative analyses to identify specific wavelengths of local minima, maxima, and inflection points. This type of derivative analysis is widely used in remote sensing (e.g., Becker et al., 2005) and provides an effective means of highlighting variations in spectral shape that might be obscured by differences in overall brightness among classes.

These procedures allowed us to compile a condensed list of key wavelengths potentially useful for classifying bottom types. To further reduce the data and efficiently exploit spectral information, we defined a set of spectral indices as slopes $\left[R\left(\lambda_{2}\right)-R\left(\lambda_{1}\right)\right] /\left[\lambda_{2}-\lambda_{1}\right]$ and ratios $R\left(\lambda_{2}\right) / R\left(\lambda_{1}\right)$ for each successive pair of wavelengths. The discriminatory power of all indices was evaluated using box plots and one-way ANOVAs, with index values grouped by sediment facies and by algal density ranking. The goal of this analysis was to identify a parsimonious collection of input variables for classifying bottom types. Three different sets of input variables were considered: (i) reflectances at 8 key wavelengths; (ii) a group of 16 spectral indices that in- 
cluded reflectance at the two most important wavelengths as well as 7 spectral slopes and 7 band ratios; and (iii) a combination of all key wavelengths and spectral indices, a total of 22 spectral features.

Although this study developed an approach to riverbed mapping based on field observations, ultimately we intend to apply these methods to remotely sensed data. Motivated by this goal, we convolved the field spectra to three different sets of sensor band passes: (i) the WorldView2 (WV2) multispectral satellite used previously to map bathymetry (Legleiter and Overstreet, 2012); (ii) the hyperspectral Compact Airborne Spectrographic Imager (CASI) evaluated by Legleiter et al. (2016), consisting of 18 bands within the 400 to 900 nm range; and (iii) a higher spectral resolution CASI configuration with 35, narrower, visible and NIR bands. We repeated OBRA for each set of convolved spectra to evaluate the feasibility of depth retrieval, a prerequisite for inferring bottom reflectance from above-water measurements. In addition, we used the convolved spectra to quantify spectral separability among the original seven facies and five algal density rankings in terms of the JeffriesMatusita distance metric described by Richards and Jia (2006, p. 273).

\subsection{Bottom reflectance retrieval}

Numerous methods for retrieving bottom reflectance have been developed by coastal researchers interested in mapping coral reefs, seagrass, and other benthic features; Zoffoli et al. (2014) provided a recent review of these techniques. One of the most popular approaches stems from the work of Maritorena et al. (1994) and remains widely used (e.g., Purkis and Pasterkamp, 2004; O'Neill et al., 2011). Briefly, we implemented the Maritorena model by (i) converting the NIR-standardized reflectance spectra to remote sens- 
ing reflectances in air just above the water surface, denoted by $R_{r s, A}(\lambda)$, by assuming Lambertian behavior and dividing by $\pi$ sr; (ii) accounting for transmission and refraction at the air-water interface to compute the remote sensing reflectance just beneath the water surface, denoted by $R_{r s, W}(\lambda)$, as (Lee et al., 2002):

$$
R_{r s, W}(\lambda)=\frac{R_{r s, A}(\lambda)}{\left[0.52+1.7 R_{r s, A}(\lambda)\right]}
$$

(iii) defining the volume reflectance of optically deep water $R_{r s, D}(\lambda)$ as the mean of the $R_{r s, W}(\lambda)$ values for the deepest $0.5 \%$ of our field spectra; and (iv) rearranging the Maritorena et al. (1994) shallow-water reflectance model

$$
R_{r s, W}(\lambda)=R_{r s, B}(\lambda) e^{-2 K_{d}(\lambda) d}+R_{r s, D}(\lambda)\left[1-e^{-2 K_{d}(\lambda) d}\right]
$$

to obtain an expression for the remote sensing reflectance of the bottom, denoted by $R_{r s, B}(\lambda)$ :

$$
R_{r s, B}(\lambda)=\frac{R_{r s, W}(\lambda)-R_{r s, D}(\lambda)\left[1-e^{-2 K_{d}(\lambda) d}\right]}{e^{-2 K_{d}(\lambda) d}}
$$

Equation (3) describes the total remote sensing reflectance, with the first term on the right-hand side representing the contribution from the bottom. This contribution is strongest in shallow, clear water $\left(R_{r s, W} \rightarrow R_{r s, B}\right.$ as $d \rightarrow 0$ and/or $\left.K_{d} \rightarrow 0\right)$ but dampened in deeper, more turbid water. The second term in Eq. (3) represents the contribution to $R_{r s, W}(\lambda)$ from the water column and implies that $R_{r s, B} \rightarrow 0$ as $d \rightarrow \infty$ and/or $K_{d} \rightarrow \infty$. The denominator in Eq. (4) accounts for attenuation of light within the water column by using $2 K_{d}(\lambda)$ to summarize the absorption and scattering that occurs as photons travel to and from the bed. After retrieving $R_{r s, B}(\lambda)$, we used the same key wavelengths and spectral indices as the above-water spectra in subsequent analyses. 


\subsection{Spectrally based classification and accuracy assessment}

We performed classifications of sediment facies and algal density rankings using above-water field spectra and inferred bottom reflectances. Field data were randomly, evenly split into training and validation subsets, with the same partition used across all classifications. We used six different sets of predictor variables (spectral indices, key wavelengths, key wavelengths and spectral indices, and spectra convolved to three different sensor band passes) to perform classifications of sediment facies and algal density for the original and for the aggregated categorizations, based on either above-water field spectra or bottom reflectance. The various combinations of substrate categories and input variables resulted in a total of 48 classifications.

All classifications were produced using random forests. This method was developed by Breiman (2001) and has become a powerful tool for remote sensing; Lawrence et al. (2006) and Cutler et al. (2007) summarized the approach and its advantages. Random forests are well suited to the case where no single variable or small group of variables can effectively distinguish among classes. The algorithm is essentially a bootstrap aggregation operation in which a specified number of classification trees are developed, each based on a random sample of training data as well as a random subset of input variables. Observations are allocated to a particular class based on votes cast by the individual trees. Unlike standard decision tree classifiers, which require laborious and subjective pruning, random forests are robust to overfitting. The method is easy to implement, requiring the user to specify only the number of trees and the number of input variables used at each tree split. Random forests also provide an estimate of classification error using 
data randomly withheld from each tree, referred to as 'out-of-bag' observations (Lawrence et al., 2006). In addition, because only a subset of the input variables are used in each iteration of tree development, the same out-ofbag observations can be used to quantify variable importance (Cutler et al., 2007). In a geomorphic context, Buscombe et al. (2014) mapped sand, gravel, and rock along the Colorado River by applying a decision tree classifier to high frequency acoustic backscatter data collected from a boat.

For each of the 48 classifications, random forests consisting of 100 decision trees were generated using the TreeBagger function in the MATLAB Statistics and Machine Learning Toolbox (MathWorks, 2016). We plotted the out-of-bag classification error against the number of trees to identify the number of trees beyond which accuracy ceased to improve. Variable importance plots were used to identify which spectral features had the greatest power to distinguish among substrates. We used the validation subset withheld from training to perform a separate, independent accuracy assessment, which we summarized in terms of overall classification accuracies and confusion matrices

\subsection{Hypothesis testing}

An important goal of this investigation was to determine which type(s) of spectral information provided the most reliable classifications of bottom type. We addressed this research question by formulating a set of hypotheses to assess whether (1) retrieving bottom reflectance enabled more accurate classification of the riverbed; (2) indices of spectral shape improved classification accuracies relative to the original spectra; and (3) sensors with higher spectral resolution provided greater classification accuracy. The hypothe- 
Table 1

Hypotheses regarding spectrally based classification of river substrates

\begin{tabular}{cl}
\hline Hypothesis & Description \\
\hline $1_{0}$ & Classifications based on above-water field spectra are at least as accurate \\
& as classifications based on retrieved bottom reflectance \\
$1_{a}$ & Classifications based on retrieved bottom reflectance are more accurate than \\
& classifications based on above-water field spectra \\
$2_{0}$ & Classifications based on reflectance magnitude are at least as accurate as \\
& classifications based on reflectance and on spectral shape \\
$2_{a}$ & Classifications based on reflectance and spectral shape are more accurate \\
& than classifications based on reflectance magnitude \\
$3_{0}$ & Classifications based on sensors with lower spectral resolution are at least as \\
& Classifications based on sensors with higher spectral resolution are more \\
$3_{a}$ & accurate than classifications based on sensors with lower spectral resolution \\
\hline
\end{tabular}

ses listed in Table 1 were evaluated by performing one-tailed, mid $p$-value McNemar tests (Lancaster, 1961) with MATLAB's testcholdout function. Separate tests were conducted for the validation subset for all combinations of features (original and aggregated categorizations of facies and algal density) and input variables (spectral indices, key wavelengths, and convolved spectra for above-water and bottom reflectance) relevant to each hypothesis.

\subsection{Preliminary remote sensing case study: CASI image of Rusty Bend}

To assess the feasibility of mapping riverbed composition from remotely sensed data, we applied the techniques we developed for field spectra to an image of Rusty Bend. This site was examined by Legleiter et al. (2016), who provide further information on the study area, sensor characteristics, image 
processing, and depth retrieval. To summarize, Rusty Bend is a single-thread reach of the Snake River with a shallow point bar along the inner bank and a deep pool along the outer bank. Hyperspectral image data with 0.6-m pixels and 18 bands between 400 and $900 \mathrm{~nm}$ were acquired by the CASI sensor on 21 August 2012. Atmospheric correction was performed using ATCOR (ReSe, 2014), a mask highlighting the wetted channel was created, and a spatial smoothing filter applied. Optimal band ratio analysis based on field measurements of depth collected within a few days of image acquisition provided a relation between $X$ and $d$ that was applied throughout the image to produce a depth map. Validation using independent field data indicated highly accurate depth retrieval, with an observed vs. predicted $R^{2}$ of 0.93 and a standard error of $0.15 \mathrm{~m}$, relative to a reach mean depth of $0.85 \pm 0.53$ $\mathrm{m}$ and a maximum depth of $2.82 \mathrm{~m}$.

Bottom reflectance was retrieved from the CASI image by applying the procedure outlined in section 2.4 using the $K_{d}(\lambda)$ calculated from field measurements. A site-specific estimate of deep water reflectance was obtained by calculating $R_{r s, D}(\lambda)$ as the mean of the $R_{r s, W}(\lambda)$ values from the deepest $0.5 \%$ of the pixels within the reach. Spectra were extracted from the original and bottom reflectance images at the locations of substrate photos acquired from the cataraft. We used the algal density rankings assigned to these photos to calculate the mean and standard deviation of the CASI reflectance spectra and retrieved $R_{r s, B}(\lambda)$ spectra for each ranking.

The extracted spectra and corresponding rankings also were used to classify algal density with the random forest algorithm. Separate classifications were produced for the CASI and bottom reflectance images, and an accu- 
racy assessment similar to that of the field spectra was performed. Unlike the field data, which were restricted to point measurements at a small number of locations, classifying the image resulted in continuous maps of algal density, with each pixel assigned to one of the four ranks we observed in Rusty Bend. In addition to the random forest classifications, we also created unsupervised, spectrally driven classifications from the CASI and $R_{r s, B}(\lambda)$ images. A $k$-means algorithm (Lloyd, 1982) was used to create four clusters that served to identify natural spectral groupings within the original and bottom reflectance images.

\section{Results}

\subsection{Observations of river spectral characteristics and bed composition}

Raw field spectra from the Snake River were subject to several sources of noise, but the simple NIR standardization procedure adapted from (O'Neill et al., 2011) reduced these extraneous sources of variability. Subtracting the mean reflectance between 850 and $900 \mathrm{~nm}$ across the spectrum accounted for (i) reflectance drift due to the passage of time between readings of the white reference panel; (ii) variable sun glint caused by differences in viewing and illumination geometry and hydraulically driven water surface roughness; and (iii) potentially other sources of instrumental and environmental noise. Comparing the raw and standardized spectra in Figs. 2A and $\mathrm{B}$ indicates that bright outliers were removed and spectral features accentuated, such as a valley at $675 \mathrm{~nm}$ and a peak at $810 \mathrm{~nm}$. The OBRA of the original and NIR-standardized spectra provided further evidence of the improvement resulting from this correction. Whereas the raw field spectra yielded a modest 
OBRA $R^{2}$ of $0.736, R^{2}$ increased to 0.865 for the standardized spectra, indicating a stronger correlation with depth. The OBRA matrices also indicated that a broader range of wavelengths, including some in the NIR around 810 $\mathrm{nm}$, were potentially useful for depth retrieval (Figs. 2C and D). Because depth is the primary control on reflectance in shallow, clear rivers, stronger $X$ vs. $d$ relations obtained from the NIR-standardized spectra implied that $R^{\prime}(\lambda)$ would be more useful for inferring other river attributes, such as bed composition.

Visual interpretation of streambed photos indicated that the substrate of the Snake River primarily consists of a gravel/cobble facies, with lesser amounts of clean gravel, sand, cobble, and various grain size mixtures (Fig. 3A). Aggregating the original seven facies to a more general set of three grain size categories further emphasized the predominance of gravel/mixture and the much less frequent occurrence of sand or cobble facies (Fig. 3B). Similarly, algal densities tended to be low, with 1 the modal rank and only $10.7 \%$ of the 3377 streambed photos assigned to the three highest rankings (3 to 5; Fig. 3C). Aggregating the original five ranks to low, medium, and high categories resulted in a vast majority classified as low; Fig. 3D illustrates the rarity of very dense patches of algae. To summarize the association of different sediment facies with various algal densities, we cross-tabulated the two attributes (Table 2). Whereas the lower algal densities (ranks 1 and 2) were distributed among all sediment facies, relatively dense patches of algae (ranks 4 and 5) occurred only in the gravel/cobble facies, the most common sediment texture along the Snake. For the aggregated categorizations, all 169 photos with high algal density were located in the gravel/mixture facies. 

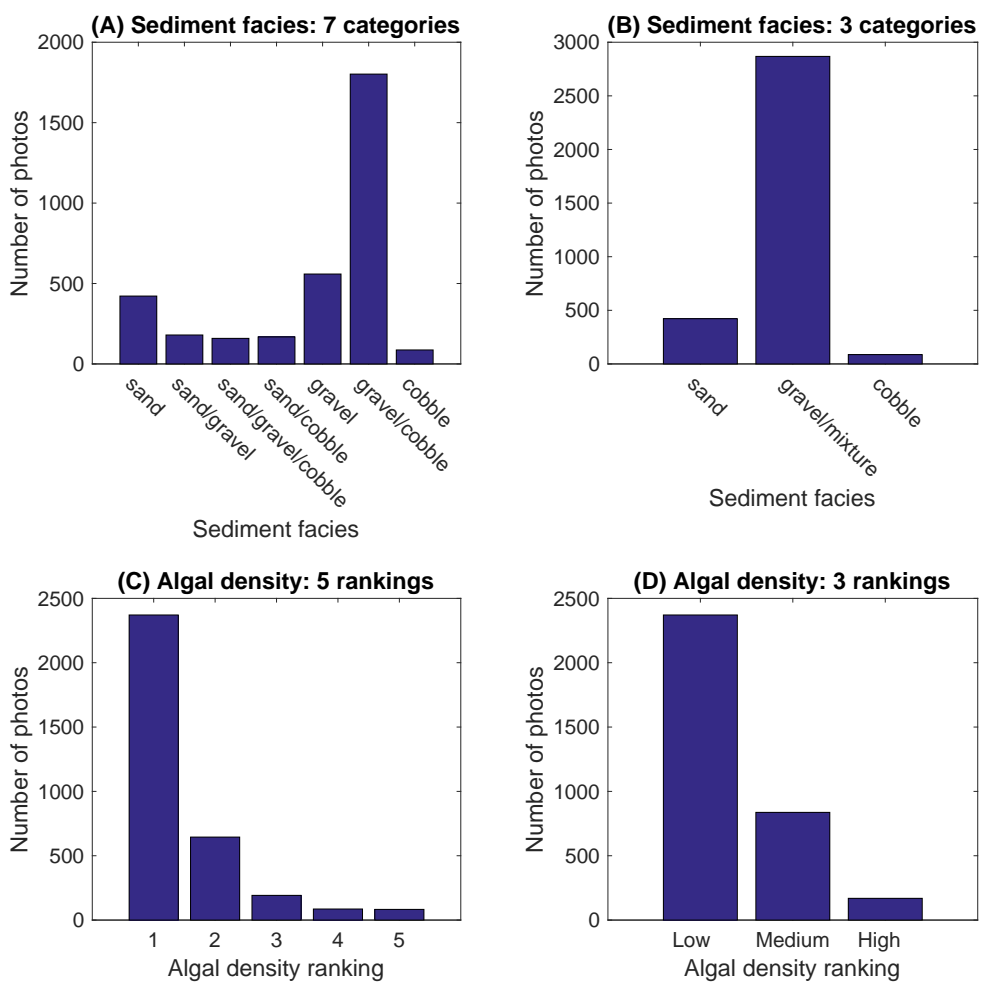

Fig. 3. Distributions of sediment facies and algal density rankings observed in riverbed photos for the (A) original seven and (B) aggregated three facies and for the (C) original five and (D) aggregated three algal density rankings. 
Table 2

Cross-tabulation of sediment facies and algal density rankings observed in riverbed photos, for both original (left) and aggregated (right) categorizations ${ }^{\mathrm{a}}$

\begin{tabular}{c|cccccc|ccc}
\hline \multicolumn{9}{c}{ Algal density } & \multicolumn{5}{c}{ Algal density } \\
Facies & $\mathbf{1}$ & $\mathbf{2}$ & $\mathbf{3}$ & $\mathbf{4}$ & $\mathbf{5}$ & Facies & Low & Medium & High \\
\hline s & 372 & 48 & 2 & 0 & 0 & $\mathbf{s}$ & 372 & 50 & 0 \\
s/g & 171 & 9 & 0 & 0 & 0 & g/m & 1977 & 722 & 169 \\
s/g/c & 159 & 0 & 0 & 0 & 0 & $\mathbf{c}$ & 22 & 65 & 0 \\
s/c & 153 & 15 & 0 & 0 & 0 & & & & \\
g & 546 & 13 & 0 & 0 & 0 & & & & \\
g/c & 948 & 506 & 179 & 86 & 83 & & & & \\
c & 22 & 54 & 11 & 0 & 0 & & & & \\
\hline
\end{tabular}

a Facies codes include: $\mathrm{s}=$ sand, $\mathrm{g}=$ gravel, $\mathrm{c}=$ cobble, and $\mathrm{m}=$ mixture. Algal densities are ordinal rankings from 1 (low) to 5 (high), or low, medium, and high for the aggregated categorization 
The reflectance characteristics of various sediment facies and algal densities potentially were confounded with the effects of water depth. Box plots and ANOVAs indicated that mean depths differed substantially among sediment facies and algal densities (Fig. 4). Sand and mixed facies with sand tended to occur in deeper water, although this observation could reflect preferential sampling of a deep, fine-grained backwater at Swallow Bend. Gravel and cobble were found in shallower water on average, but depth distributions for these facies were quite broad, particularly for the most commonly occurring gravel/cobble bottom. Figure 4B shows that depth was inversely correlated with algal density, with the most well-developed algae patches tending to occur in shallower water than the lower density rankings.

Combining field spectra with streambed photos allowed us to link the reflectance characteristics of the Snake River to the composition of its bottom. Mean spectra for the various sediment facies revealed an inverse correlation between reflectance and grain size that was consistent from 400 to $900 \mathrm{~nm}$ (Fig. 5A). On average, sand was brightest and cobble darkest; but all facies had fairly similar spectral shapes. Reflectance rose steadily throughout the blue to a peak in the green followed by a sharp decrease in reflectance from 570 to $600 \mathrm{~nm}$, a more gradual decline through the red except for an absorption band at $675 \mathrm{~nm}$, followed by an abrupt decrease into the NIR and very low reflectances beyond $735 \mathrm{~nm}$ except for a minor peak at 810 nm. For the aggregated categorization of facies in Fig. 5B, differences between the brighter sand, darker cobble, and intermediate gravel/mixture facies were more pronounced. For the original algal density rankings in Fig. $5 \mathrm{C}$, reflectance magnitude varied less among rankings than among facies but 
(A) Depth (m) grouped by sediment facies

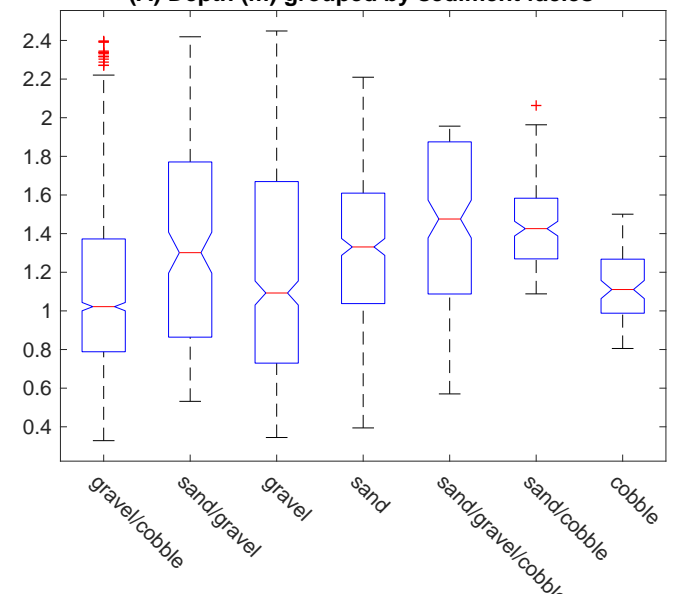

(B) Depth (m) grouped by algal density rănking

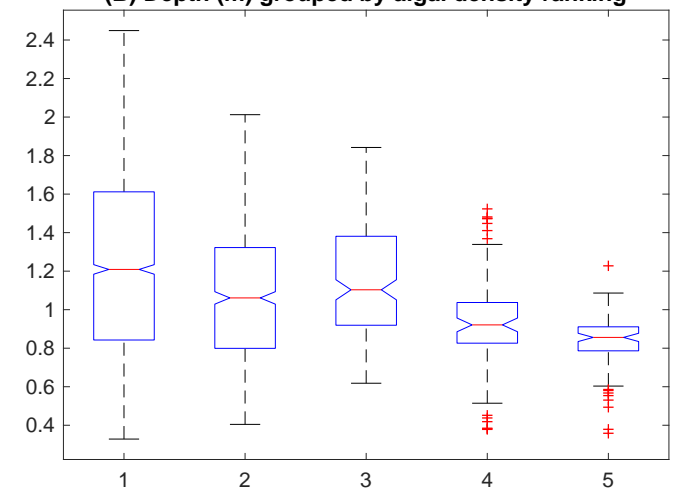

Fig. 4. Box plots of water depth grouped by (A) sediment facies and (B) algal density. 
differences in shape were more evident. The most notable spectral feature was a valley at $675 \mathrm{~nm}$, where stronger chlorophyll absorption caused lower reflectance for higher algal density rankings. Distinctions among algal densities were more pronounced when aggregated to low, medium, and high; the much deeper chlorophyll absorption for high algal density stands out in Fig. $5 \mathrm{D}$.

Another important optical property that must be known to retrieve bottom reflectance is the rate at which light is attenuated by the water column, which we summarized by calculating the diffuse attenuation coefficient $K_{d}(\lambda)$. This analysis was reported previously in Fig. 3 of Legleiter et al. (2016). During late summer, the Snake River has low concentrations of suspended sediment and very little dissolved organic matter and thus is characterized by low values of $K_{d}(\lambda)$, particularly in the green and red wavelengths. At shorter blue wavelengths, greater attenuation is caused by scattering by suspended sediment and attenuation increases abruptly into the NIR because of strong absorption by pure water. Our field observations of water column attenuation thus imply a high degree of water clarity conducive to bottom reflectance retrieval, at least for green and red wavelengths with small $K_{d}(\lambda)$.

\subsection{Spectral analysis and variable selection}

Visual inspection of the mean spectra in Fig. 5 suggested that various sediment facies and algal densities could be distinguished by their reflectance characteristics, and we sought to make such distinctions based on a reduced set of input variables. The eight key wavelengths we identified, listed in Table 3 and illustrated in Fig. 5, included a peak in the green, inflection points on the descending limb from this peak, the chlorophyll absorption 

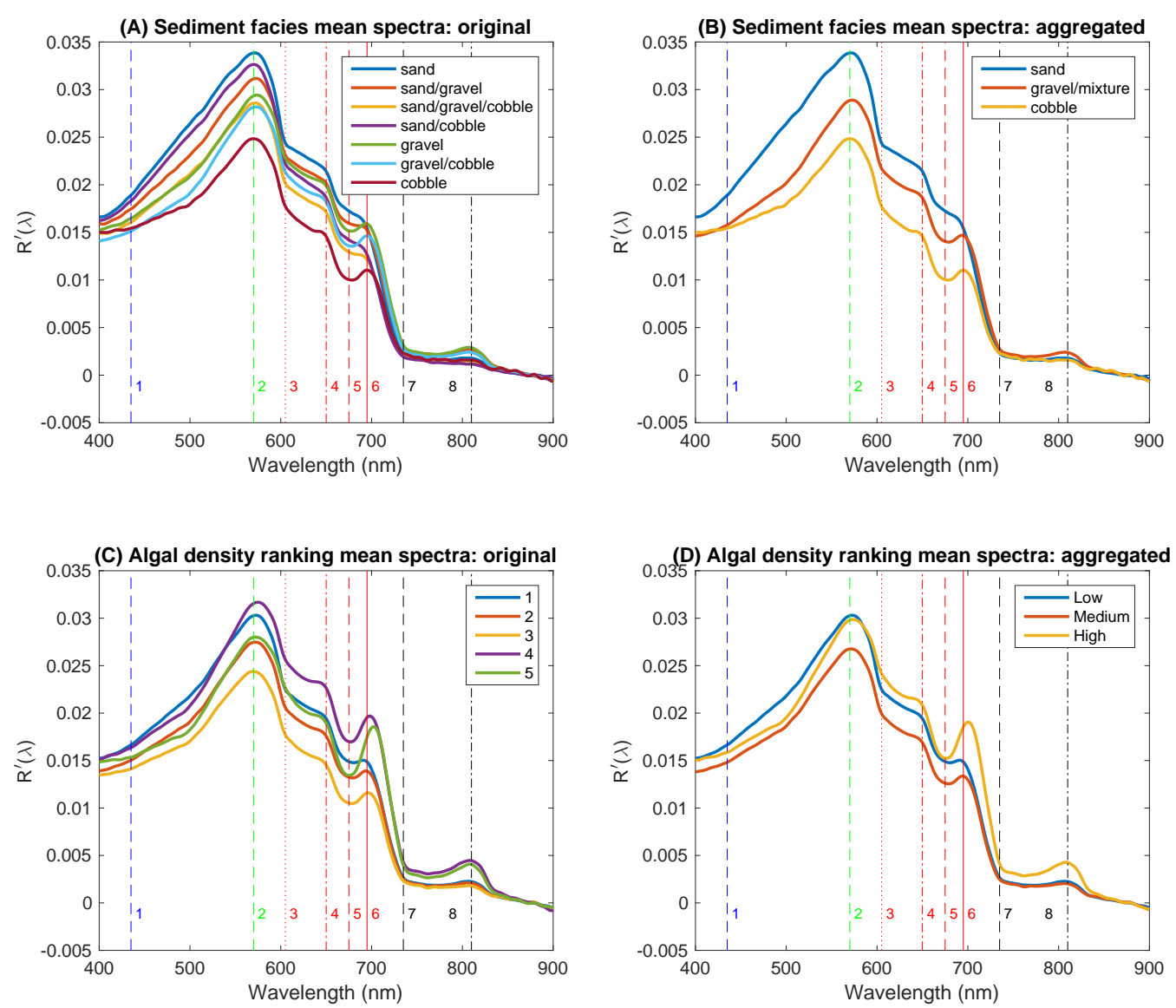

Fig. 5. Mean above-water field spectra for (A) original and (B) aggregated sediment facies and (C) original and (D) aggregated algal density rankings. The vertical lines indicate key wavelengths listed in Table 3. 
feature centered at $675 \mathrm{~nm}$, and a smaller secondary peak in reflectance at 810 $\mathrm{nm}$. Reflectance values for these wavelengths provided information on overall brightness that might be useful for distinguishing among sediment facies. The various algal densities had similar reflectance magnitudes, however, so we defined indices of spectral shape (slopes and ratios) unaffected by brightness.

The potential of these 22 spectral features to distinguish among substrates was confirmed by box plots and ANOVAs indicating that all key wavelengths and indices had mean values that differed significantly among the various sediment and algae categories $(p<0.0001)$, although the high level of statistical significance was driven at least in part by large sample sizes. Nevertheless, these results justified using the variables in Table 3 as inputs for riverbed classification. For example, a simple chlorophyll absorption ratio defined as $C A R=R^{\prime}(695) / R^{\prime}(675)$ provided clear separation among algal densities, particularly for the two highest rankings (Fig. 6).

\subsection{Bottom reflectance retrieval}

We evaluated the hypothesis that inferring bottom reflectance would facilitate spectrally based mapping of riverbed composition by applying the Maritorena et al. (1994) shallow water reflectance model to NIR-standardized field spectra. This algorithm resulted in reasonable values of $R_{r s, B}(\lambda)$ from 450 to $700 \mathrm{~nm}$ but unrealistically high or negative values at shorter blue wavelengths and particularly in the NIR caused by strong absorption by water. A source of uncertainty that might have affected the $R_{r s, B}(\lambda)$ spectra was our characterization of the deep-water reflectance $R_{r s, D}(\lambda)$ as the mean of the deepest $0.5 \%$ of the spectra measured in the field. A radiative transfer model such as Hydrolight (Mobley and Sundman, 2013) could have been 
Table 3

Key wavelengths for distinguishing among sediment facies and algal densities; additional features used for classification included spectral slopes and ratios; numbers correspond to vertical lines in Figs. 5 and 7 and the horizontal axis of Figs. 9B and D

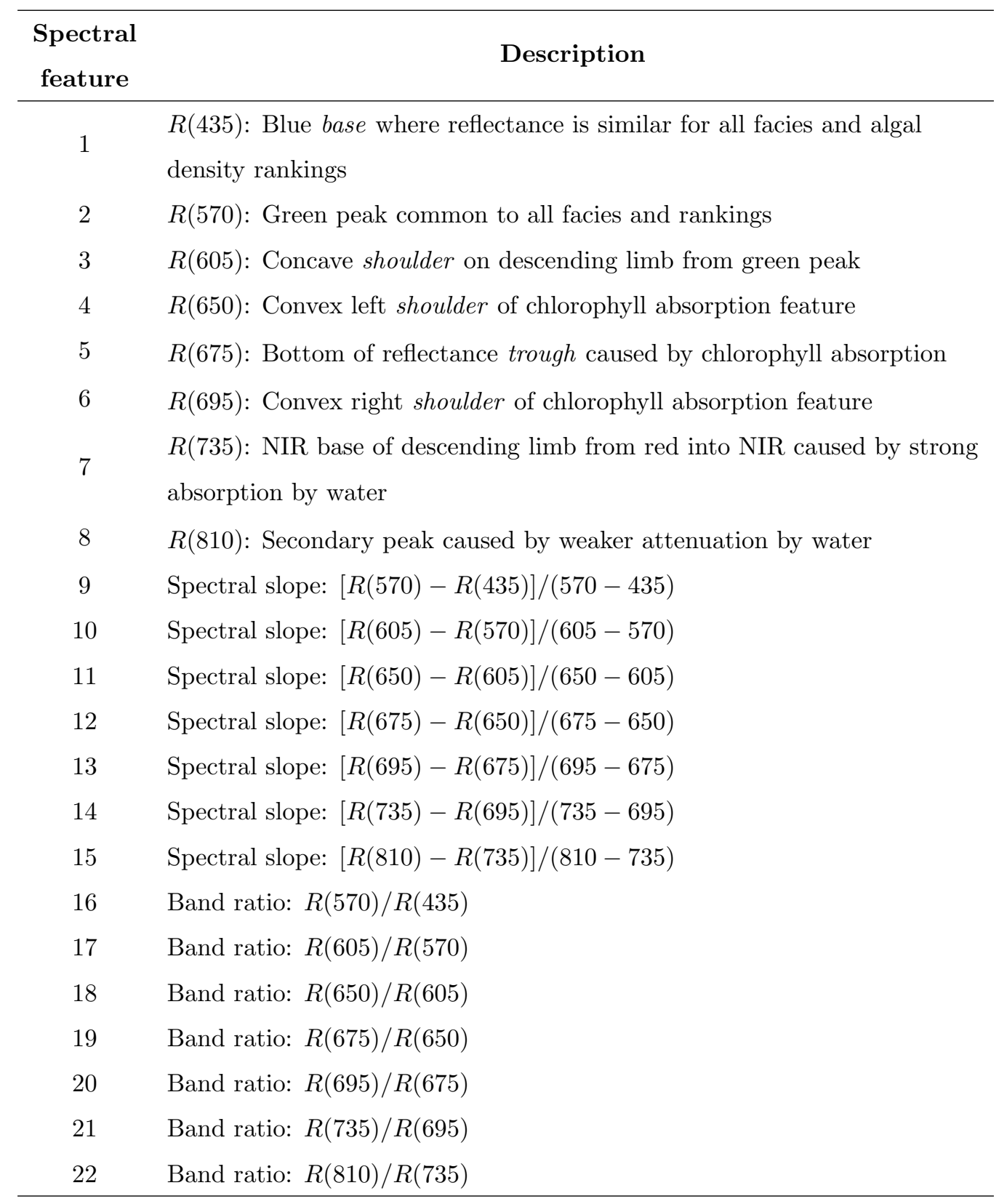




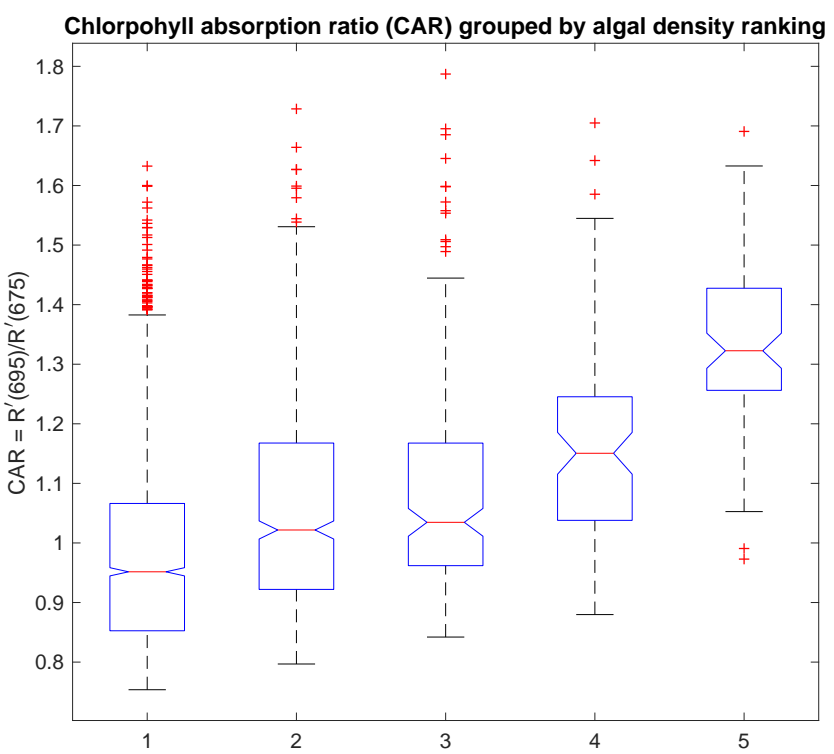

Fig. 6. Box plot of the chlorophyll absorption ratio, $C A R=R^{\prime}(695) / R^{\prime}(675)$, identified as an effective spectral index for distinguishing among different algal density rankings. 
used to simulate $R_{r s, D}(\lambda)$, but our empirical approach was simpler and more direct. The noise at shorter and longer wavelengths lead us to truncate the $R_{r s, B}(\lambda)$ spectra to 450 to $700 \mathrm{~nm}$, implying that substrate mapping based on bottom reflectance would be limited to a smaller range of wavelengths.

To assess whether inferring bottom reflectance would enhance differences among various sediment facies and algal densities, we plotted mean $R_{r s, B}(\lambda)$ spectra for the original and aggregated categorizations of the riverbed (Fig. 7). For facies, the trend of higher reflectance for finer-grained bed material evident in the above-water spectra became more pronounced for $R_{r s, B}(\lambda)$; sand was brightest and cobble darkest across the 450 to $700 \mathrm{~nm}$ range. Coarser facies also had more variable spectral shapes than sand or mixtures with sand, most notably a deeper chlorophyll absorption feature. For algae, differences in retrieved bottom reflectance were more subtle, with no consistent trend in brightness across the original or aggregated density rankings. The stronger absorption at $675 \mathrm{~nm}$ for the higher density rankings noted in the above-water spectra remained evident for $R_{r s, B}(\lambda)$ as well.

Although this study was based on field spectra, we also sought to assess whether our approach to inferring bottom reflectance and classifying the riverbed could be applied to remotely sensed data. The Maritorena et al. (1994) model requires information on water depth, so we first evaluated whether field spectra convolved to the bands of the WV2, CASI 18-band, and CASI 35-band sensors would yield accurate depth estimates. The results summarized in Table 4 indicated that these instruments provide sufficient spectral information to enable reliable depth retrieval, though somewhat less so for the broader bands of the WV2 multispectral satellite. Doubling the 

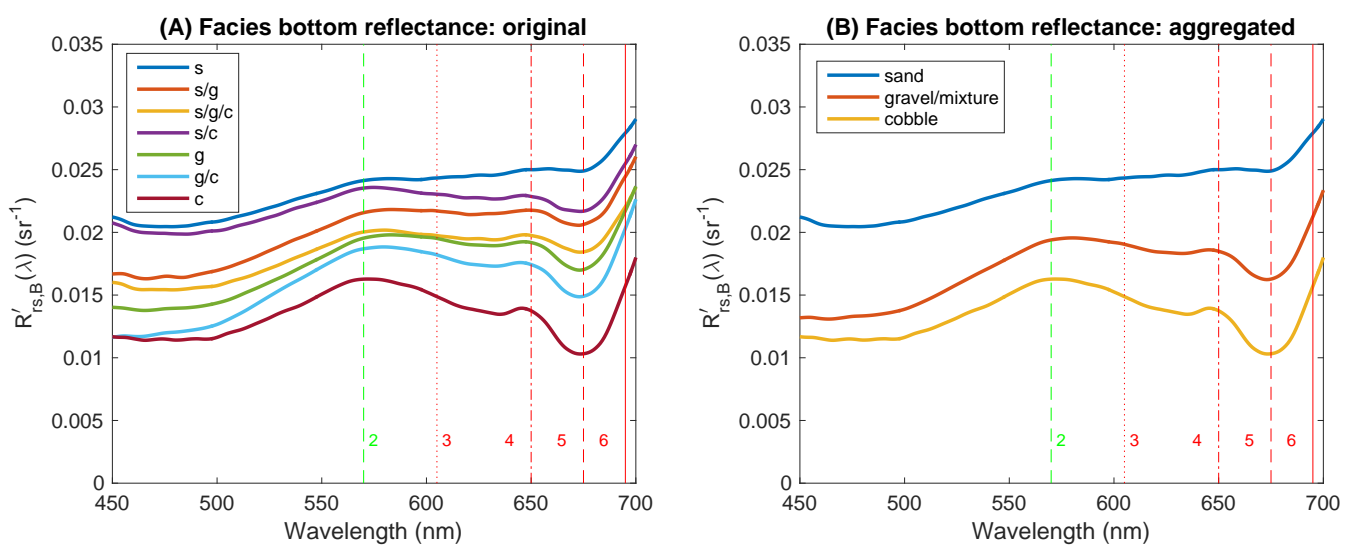

(C) Algal density bottom reflectance: original
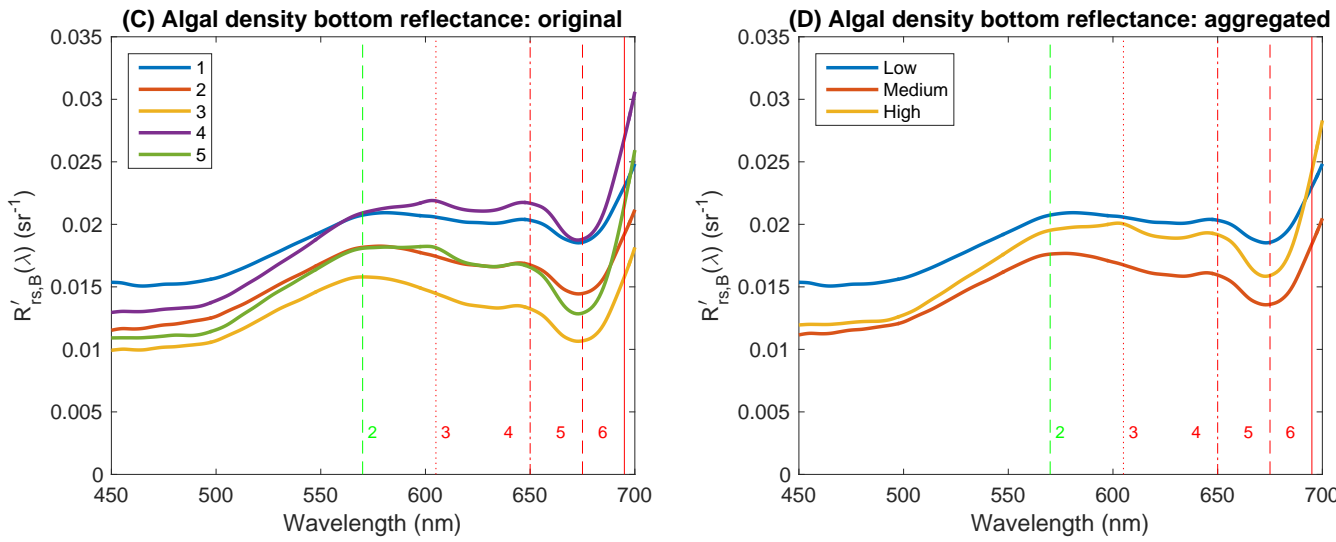

Fig. 7. Mean retrieved bottom reflectance spectra for (A) original and (B) aggregated sediment facies and (C) original and (D) aggregated algal density rankings. The letters textits, $g$, and $c$ in the legend for (A) refer to sand, gravel, and cobble. The vertical lines indicate key wavelengths listed in Table 3 . 
Table 4

Summary of optimal band ratio analysis (OBRA) of standardized field spectra (Fig. 2B) convolved to the band passes of three different remote sensing instruments (for comparison to the full-resolution field spectra, refer to the OBRA results summarized in Fig. 2D); $\lambda_{1}$ and $\lambda_{2}$ refer to the center wavelengths of the numerator and denominator bands, respectively

\begin{tabular}{ccccccc}
\hline Sensor & $\begin{array}{c}\text { OBRA } \\
R^{2}\end{array}$ & $\begin{array}{c}\lambda_{1} \\
(\mathbf{n m})\end{array}$ & $\begin{array}{c}\lambda_{2} \\
(\mathbf{n m})\end{array}$ & $\begin{array}{c}\text { Regression } \\
\text { slope }\end{array}$ & $\begin{array}{c}\text { Regression } \\
\text { intercept }(\mathbf{m})\end{array}$ & $\begin{array}{c}\text { Standard } \\
\text { error }(\mathbf{m})\end{array}$ \\
\hline WorldView2 & 0.775 & 545 & 605 & 3.16 & 0.597 & 0.22 \\
CASI-18 & 0.844 & 633.6 & 690.7 & 3.59 & 0.0709 & 0.183 \\
CASI-35 & 0.849 & 561.3 & 703.7 & 1.13 & 0.191 & 0.18 \\
\hline
\end{tabular}

number of bands for the hyperspectral CASI system did not substantially increase the OBRA $R^{2}$.

Convolving above-water field spectra and inferred bottom reflectances to the band passes of these three sensors also allowed us to calculate metrics of spectral separability that were computationally intractable for the original, full-resolution spectra. The Jeffries-Matusita distance $J M$ quantifies the degree to which spectra from a pair of classes are distinct from one another; $J M>1.9$ implies a high degree of separability (Richards and Jia, 2006). We calculated $J M$ for all combinations of the original seven sediment facies and five algal density rankings for above-water and $R_{r s, B}(\lambda)$ spectra convolved to the band passes of the WV2, CASI-18, and CASI-35 sensors (Fig. 8). All facies and algal densities were readily separable for the sensor with the most, narrowest bands (CASI-35), although to a slightly lesser degree for $R_{r s, B}(\lambda)$ than for the above-water field spectra. For the lower spectral resolution sensors, the facies were less separable, and for WV2 only a few pairs of sediment 
categories exceeded the $J M>1.9$ threshold. For algae, the distinctions between the five density rankings were even less strong, particularly for the relatively broad bands of WV2, for which $J M<1.9$ for all combinations of rankings for the above-water field spectra (Fig. 8G). Unlike the sediment facies, comparison of Figs. 8G-J indicates that algal densities were distinguished more readily on the basis of bottom reflectance than above-water field spectra.

\subsection{Riverbed classification}

To assess the potential for mapping bottom type based on spectral information, we created 48 separate classifications and assessed their accuracy. This analysis allowed us to draw conclusions regarding the feasibility of identifying riverbed features from field spectra or remotely sensed data, to evaluate whether retrieving bottom reflectance would facilitate this objective, and to determine which input variables might provide the most reliable substrate maps. The random forest algorithm proved to be computationally efficient, with forests comprised of 100 trees and based on up to 35 input variables generated within a matter of seconds on a standard personal computer. Plots of classification error against the number of trees indicated that accuracy tended to stabilize more quickly for algal density than for sediment facies but that in both cases accuracy did not improve beyond about 50 trees (Fig. 9A and $\mathrm{C}$ ). The random forest method also provided a means of determining which wavelengths and spectral indices were most useful for discriminating among bottom types. For example, variable importance plots for the most accurate classifications of sediment facies and algal density, based on a combination of key wavelengths and spectral indices derived from above-water 

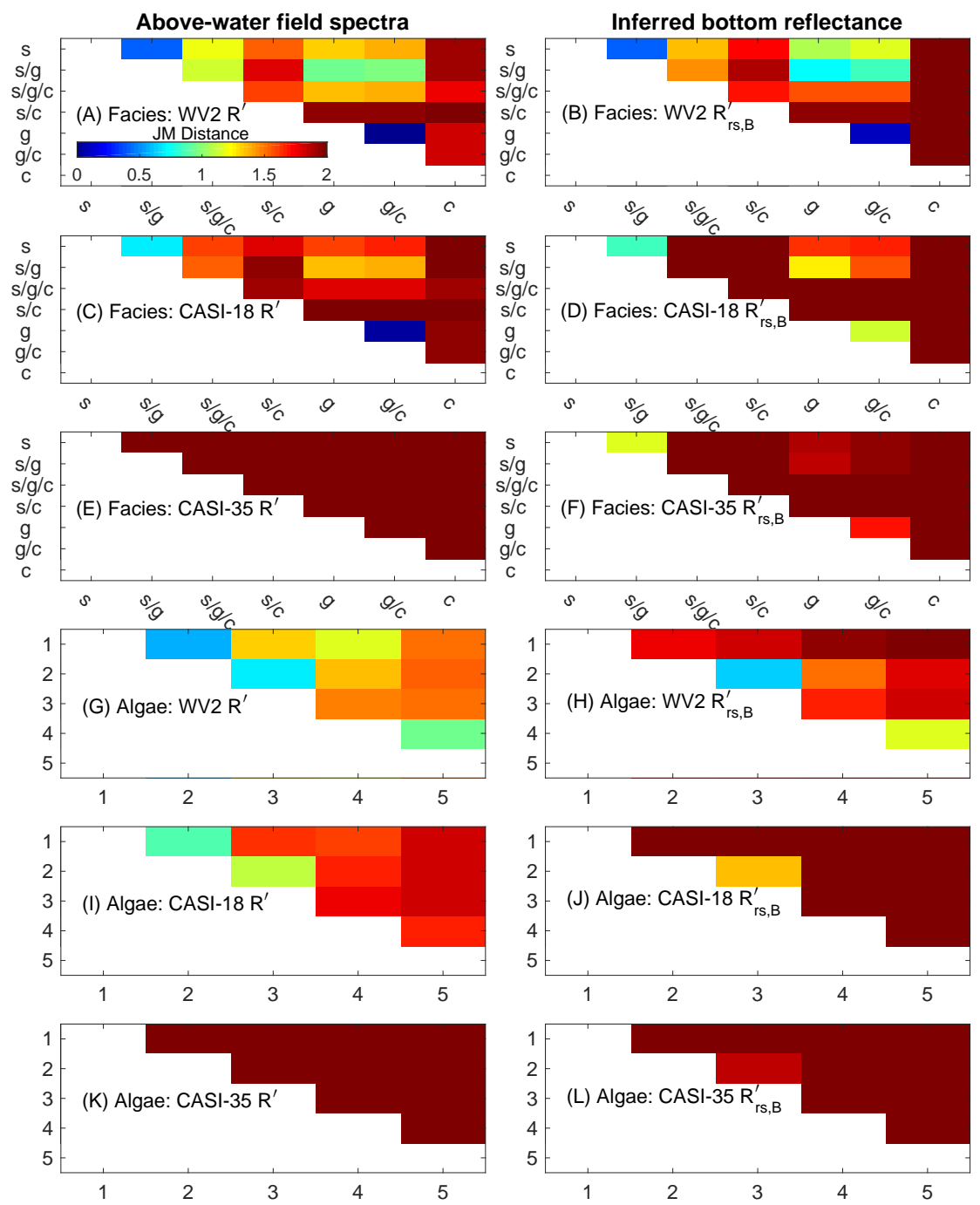

Fig. 8. Spectral separability of sediment facies and algal density rankings, quantified in terms of the Jeffries-Matusita distance $J M$, for above-water field spectra (left column) and inferred bottom reflectance (right column) convolved to the sensor band passes of the WorldView2 (WV2) satellite and Compact Airborne Spectrographic Imager (CASI) 18 and 35-band configurations. Facies codes are $s=$ sand, $g=$ gravel, and $c=$ cobble. 
spectra, are shown in Fig. 9B and D. For facies, spectral feature 1, $R^{\prime}(435)$, stood out as particularly valuable and probably served to summarize overall brightness. For algae, chlorophyll absorption was highlighted as $R^{\prime}(675)$ and $R^{\prime}(695)$ were the first and third most important variables (Fig. 9D and Table $\mathrm{S} 1)$.

Classification accuracies generally were $>0.7$ but differed between facies and algae, original and aggregated categorizations, above-water and bottom reflectance, and types of predictor variables (Fig. 10 and Table S1). The single most accurate classification (0.924) was for the aggregated categorization of sediment facies and was based on a combination of 22 key wavelengths and spectral indices derived from above-water field spectra. The same predictor variables also provided the most accurate classification of algal density, but combining the original five ranks into a low/medium/high scheme had less of an impact than did grouping facies. Comparison of the light and dark blue bars in all four panels of Fig. 10 indicated that classification accuracies were higher for above-water field spectra than for inferred bottom reflectances, but variable importance plots failed to identify any obvious diagnostic wavelengths or spectral indices for differentiating among bottom types. The frequent occurrence of reflectances at 650,675, and $695 \mathrm{~nm}$, as well as slopes and ratios including these wavelengths, among the top four predictors in Table S1 implied that chlorophyll absorption at $675 \mathrm{~nm}$ was a useful spectral feature for classification, particularly of algal density.

\subsection{Hypothesis testing}

We used 48 classifications to statistically test the hypotheses listed in Table 1, which were designed to evaluate whether retrieving bottom reflectance, 

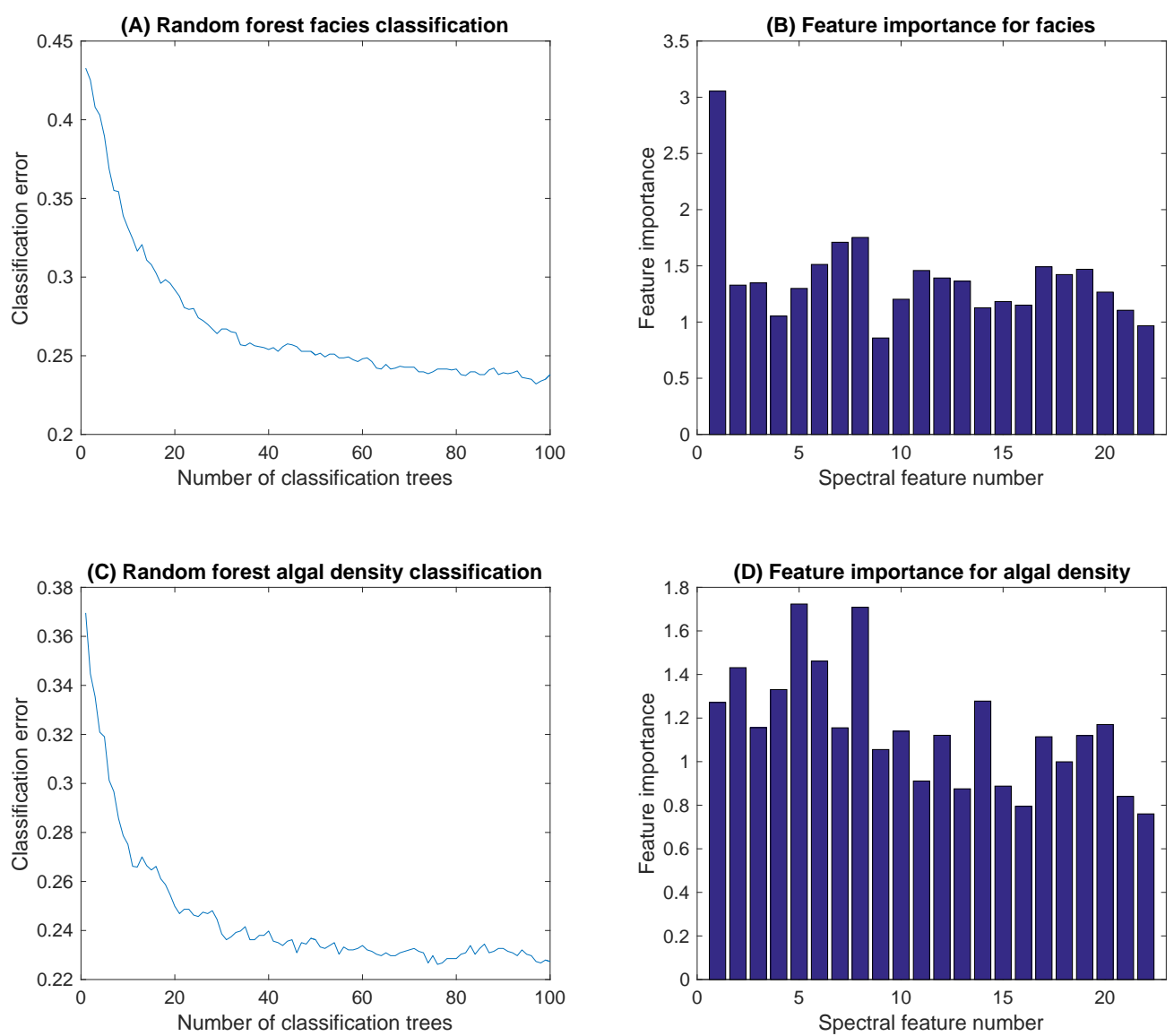

Fig. 9. Examples of random forest classifications for the input variables providing the greatest classification accuracy for above-water field spectra: a combination of key wavelengths and spectral indices. Classification error rates as a function of the number of decision trees included in the random forest are illustrated for (A) facies and (C) algal density classifications. The error rates are out-of-bag classification errors. The corresponding variable importance plots (based on out-of-bag observations) are shown in panels (B) and (D). Spectral features are listed in Table 3. 

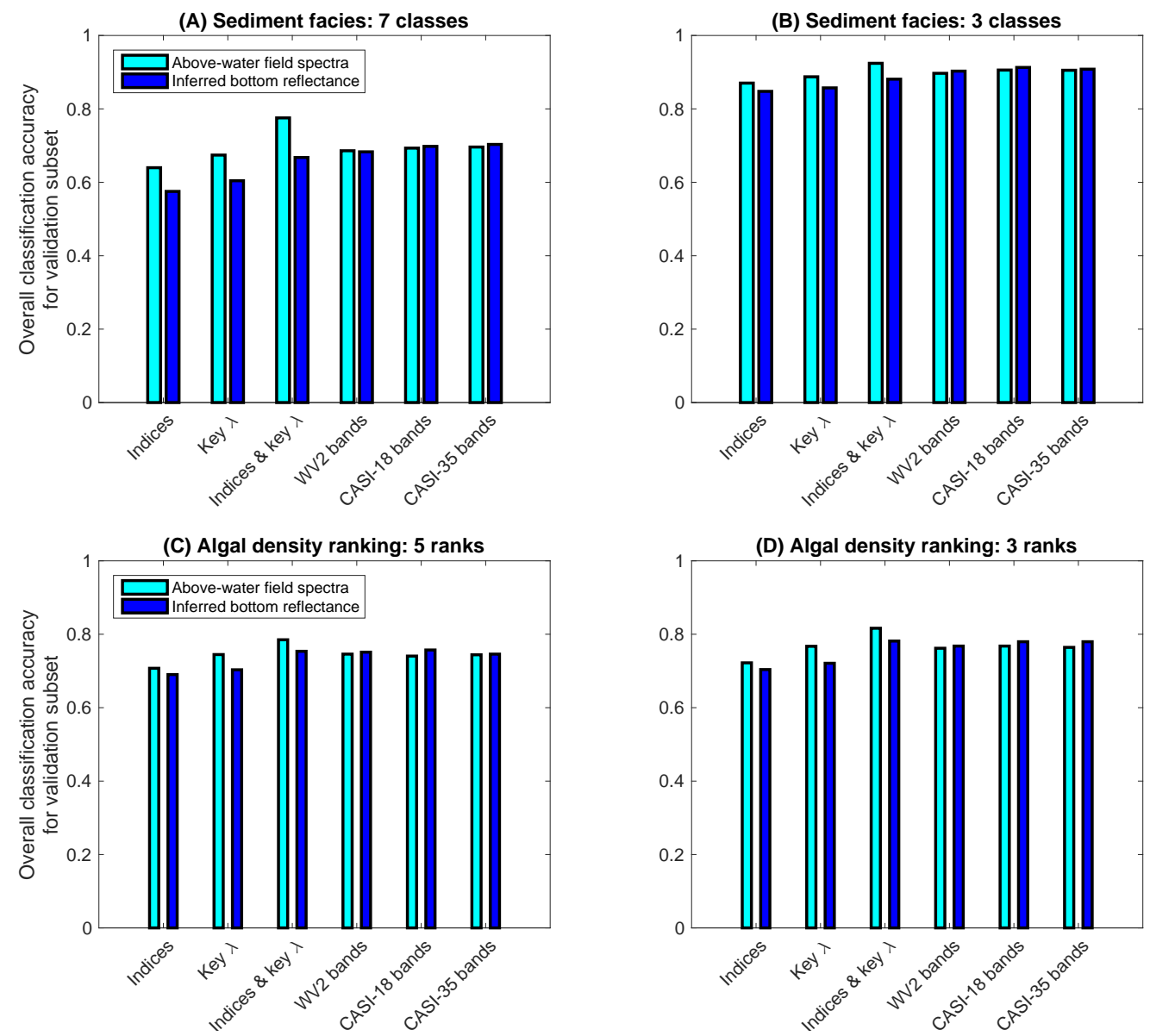

Fig. 10. Classification accuracy for sediment facies and algal density rankings for the original (A and $\mathrm{C}$ ) and aggregated (B and $\mathrm{D}$ ) categories for different input variables. 
incorporating indices of spectral shape, and using data from higher spectral resolution sensors might enable more reliable mapping of riverbed composition. We hypothesized that inferring bottom reflectance would account for the confounding effects of a water column of variable depth and thus facilitate classification of bottom type, but our results did not support this notion. For all 12 tests comparing sediment facies classifications based on above-water vs. $R_{r s, B}(\lambda)$ spectra, we failed to reject null hypothesis $1_{0}$ that retrieving bottom reflectance would not improve classification accuracy (Table S2). Similarly, for algal density we rejected null hypothesis $1_{0}$ for 9 of 13 tests, the only exceptions being for the aggregated categorization and spectra convolved to the 18- and 35-band CASI configurations (Table S3). These results implied that retrieving bottom reflectance was not essential for mapping the bed and that classifications at least as accurate could be derived from above-water field spectra.

Our second hypothesis considered the selection of spectrally based input variables to drive these classifications. Indices of spectral shape, such as slopes and ratios, yield accuracies no higher than reflectance magnitudes, suggesting that distinctions among substrates were expressed primarily as differences in overall brightness rather than spectral shape. Although indices alone were not effective discriminators of sediment facies and algal density, McNemar tests provided strong evidence $(p<0.0001)$ against null hypothesis $2_{0}$ (Tables S2 and S3). These results implied that a combination of reflectance at key wavelengths, which provide information on brightness, and metrics of spectral shape enhanced classification accuracy. Because these indices did not impose a computational burden on the random forest algorithm, measures of 
both reflectance magnitude and spectral shape should be included as input variables for riverbed classification.

For our third hypothesis, concerning sensor spectral resolution, McNemar tests indicated that a greater number of bands improved classification accuracy in some cases but not others. In general, spectral resolution had more of an effect on classification accuracy for facies $(p<0.05$ for 3 of 8 tests; Table S2) than for algal density ( $p<0.05$ for only 1 of 8 tests; Table S3). Significant improvements in accuracy were associated with an increase in spectral resolution from the WV2 multispectral satellite to the 18-band CASI configuration for facies classifications based on above-water and bottom reflectance spectra and for algal density classifications based on $R_{r s, B}(\lambda)$. In no case, however, did increasing the number of CASI bands from 18 to 35 enhance classification accuracy. These results implied that a moderate level of spectral detail could be sufficient for delineating bottom types.

\subsection{Preliminary remote sensing case study}

Although this feasibility study was based on field observations of reflectance and bottom composition, ultimately our objective was to map river substrates from remotely sensed data. As an initial step toward this goal, we examined a CASI hyperspectral image of the Snake River. A green band is displayed in grayscale in Fig. 11A, followed by the depth map and retrieved bottom reflectance in panels B and C; Figs. 11A and C are displayed with an identical $90 \%$ linear contrast stretch. Relative to the original CASI data, the $R_{r s, B}(\lambda)$ image was more variable but remained spatially coherent, accentuating features of the riverbed only subtly alluded to in the original image. For example, the bottom reflectance image clearly highlighted brightly col- 
ored clay bedrock and blocks of failed bank material exposed along the upper portion of Rusty Bend. Visual comparison of Fig. 11A and C suggested that inferring bottom reflectance might provide additional substrate information.

Also overlain on Fig. 11 are symbols indicating algal density rankings assigned to streambed photos. To examine differences in reflectance among the four rankings observed along Rusty Bend, we extracted pixel values for all bands of the original CASI and inferred bottom reflectance images and calculated mean spectra for each rank. Spectra from the original CASI image exhibited only subtle differences among the four algal density rankings except for a greater reflectance for the lowest rank (Fig. 12A). Differences among ranks were more pronounced in the inferred bottom reflectance image, with a consistent decrease in brightness with increasing algal density (Fig. 12B). Similarly, whereas chlorophyll absorption was barely evident in the original CASI image, a decrease in reflectance in the red was more pronounced in the $R_{r s, B}(\lambda)$ spectra. The $R_{r s, B}(\lambda)$ also increased less at longer wavelengths approaching $700 \mathrm{~nm}$ for higher algal densities. These distinctions, primarily expressed as a contrast in overall brightness, could be confounded with differences in depth among ranks, but the highest algal density had a median depth shallower than the two intermediate ranks and only slightly greater than the lowest density (Fig. 12C). The lack of a direct, consistent correlation between algal density and depth implies that lower reflectances for higher rankings were not driven entirely by greater depth. Instead, we attribute this inverse relationship to the greater coverage of relatively dark, strongly absorbing filamentous algae at the expense of brighter, more reflective bare sediment, as illustrated in the streambed photos in Figs. 12D to G. 


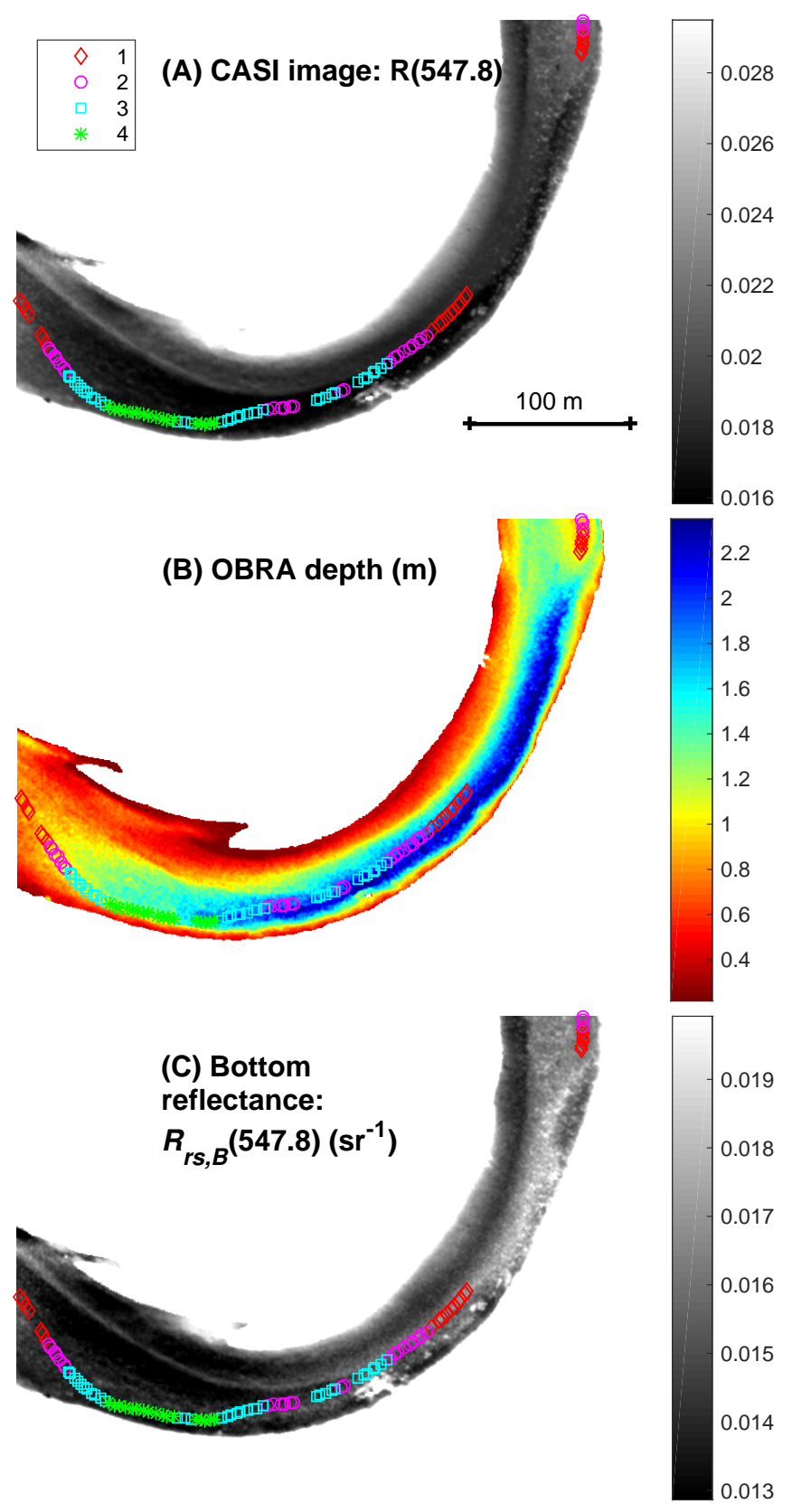

Fig. 11. An example application of bottom reflectance retrieval from a CASI hyperspectral image of Rusty Bend. Flow is from upper right to lower left. (A) Reflectance in a green band displayed with a $90 \%$ linear contrast stretch. Point symbols overlain on the image represent algal density rankings. (B) OBRA-derived depth map (Legleiter et al., 2016), displayed with a $98 \%$ linear contrast stretch $45 \mathrm{C}$ ) Bottom reflectance inferred for the same green band, also displayed with a $90 \%$ linear contrast stretch. 

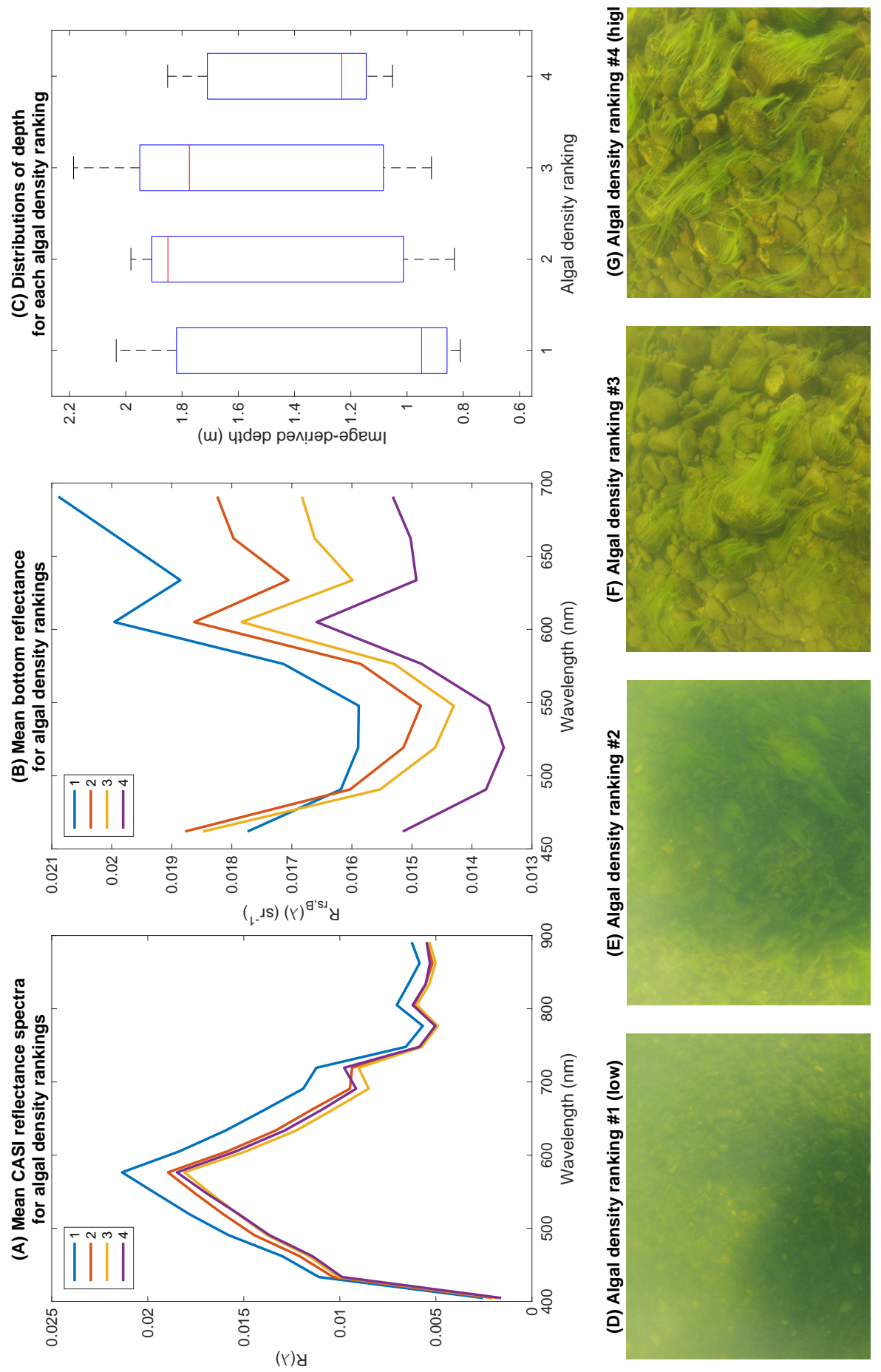

Fig. 12. Spectral characteristics of various algal density rankings from the Rusty Bend CASI image in Fig. 11. (A) Mean reflectatee spectra from the CASI image. (B) Mean inferred bottom reflectance. (C) Box plot illustrating the distribution of depths for each algal density ranking. (D-G) Example riverbed photographs for each algal density ranking. 
As an initial attempt to remotely sense riverbed composition, we used spectra extracted from the original CASI and retrieved bottom reflectance images to classify algal density. Half of the spectra were used as input to the random forest algorithm with the remainder reserved for validation. Visual comparison of the resulting classifications indicated that the algal density map derived from the bottom reflectance image was much grainier (Fig. 13). The assignment of pixels to the first two ranks also was reversed, with an intermediate rank (2) along the bar margin followed by a low rank (1) closer to the centerline in the classification based on the original CASI image and an opposite pattern in the map derived from inferred bottom reflectance. Because we lack direct field observations from this area, we cannot verify which is correct. In both cases, the two highest algal density rankings (3 and 4) were located in deeper water near the outer bank. We assessed the accuracy of each classification using streambed photos from the channel thalweg and found that the original CASI image provided a more accurate classification of algal density (0.686) than did the bottom reflectance image (0.451). The variable importance plots in Fig. 13C and D indicated that red bands encompassing the chlorophyll absorption feature were more useful in classifying the CASI reflectance image than the bottom reflectance image, for which blue and green bands were most informative.

In addition to these supervised classifications, in which the random forest assigned pixels to predefined classes based on training data, we also performed unsupervised classifications to identify natural spectral groupings that might correlate with bottom composition. We applied a $k$-means algorithm to the original CASI and inferred bottom reflectance images to produce 

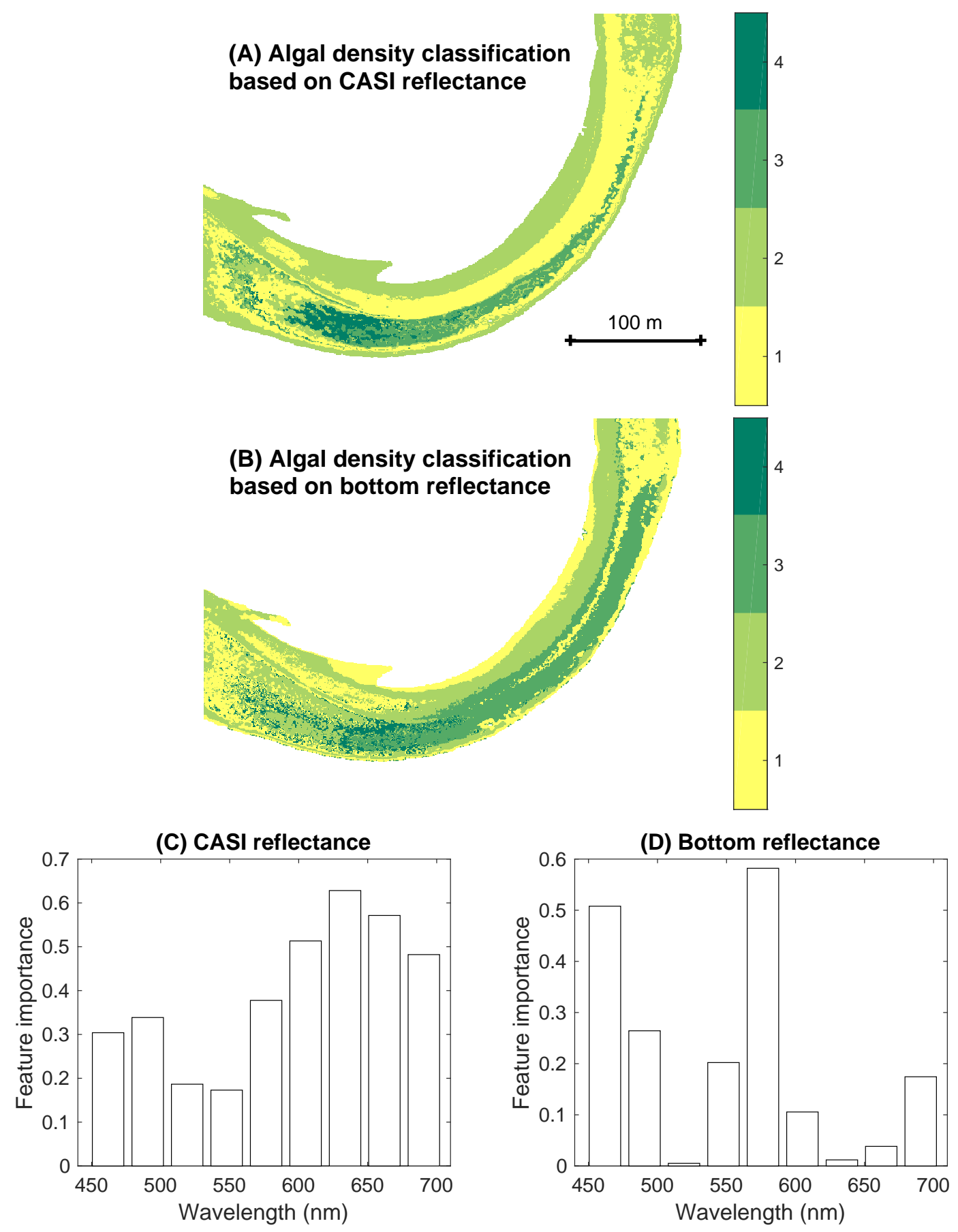

Fig. 13. Supervised random forest classifications of algal density for Rusty Bend based on (A) the CASI reflectance image and (B) bottom reflectance retrieved from the image. The corresponding variable importance plotb 8 are shown in panels $(C)$ and (D). 
four clusters, the same number of categories as the supervised classifications of algal density. Comparison of Fig. 14A and B indicates that the two images resulted in $k$-means classifications with very different spatial patterns. The clusters derived from the original CASI image were associated with water depth, producing a classification that was essentially a bathymetric contour map; note that because numbers were randomly assigned to clusters by the $k$-means algorithm, the order of the clusters with increasing depth (and thus decreasing overall brightness, Fig. 14C) was 3, 2, 1, 4. The bottom reflectance-based unsupervised classification had a distinct spatial structure that was not solely a function of depth. Although the clusters in Fig. 14B are difficult to interpret, the mean spectra for each cluster (Fig. 14D) were distinguished not only by brightness but also by spectral shape to a greater degree than were the clusters produced from the CASI image. These results suggest that retrieving bottom reflectance might reveal spectral characteristics not evident in the original image and thus provide additional information on riverbed composition. 

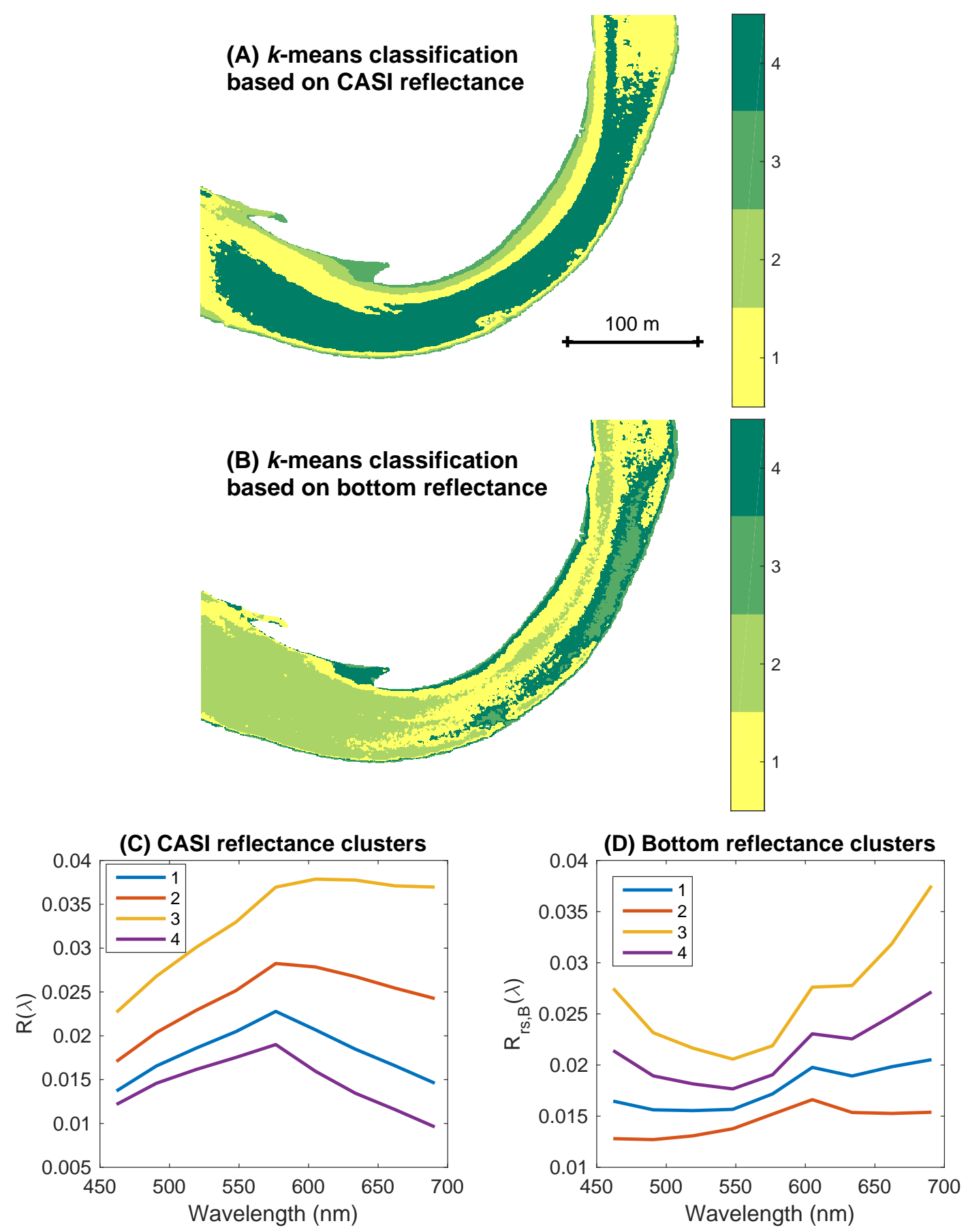

Fig. 14. Unsupervised $k$-means classifications for Rusty Bend based on (A) the CASI reflectance image and (B) bottom reflectance retrieved from the image. The corresponding cluster centroid spectra are shown in panels $5(0 \mathrm{C})$ and (D). 


\section{Discussion}

This study evaluated the potential for spectrally based mapping of riverbed composition, primarily using field measurements but also a hyperspectral image. Our results indicate that various sediment facies and algal densities observed along the Snake River were sufficiently distinct for these bottom types to be delineated on the basis of their reflectance characteristics. Moreover, we found that accurate substrate classifications could be derived from abovewater field spectra; retrieving bottom reflectance was unnecessary. The algorithm for inferring $R_{r s, B}(\lambda)$ was not cumbersome but did require knowledge of depth and water column optical properties, summarized by the diffuse attenuation coefficient $K_{d}(\lambda)$. If the bed could be mapped just as effectively from above-water measurements, as our results suggest, additional information on $d$ and $K_{d}(\lambda)$ would not be necessary and substrate classification could proceed directly from field spectra or remotely sensed data.

Another encouraging finding was that sensors with high spectral resolution were not essential. Convolving field spectra to the band passes of a multispectral satellite and 18- and 35-band configurations of a hyperspectral system indicated that more, narrower bands did not significantly improve classification accuracy. The importance of certain features, such as chlorophyll absorption at $675 \mathrm{~nm}$, implied that wavelength location might be a more important consideration than band width. A combination of reflectance magnitude at key wavelengths and indices of spectral shape (e.g., slopes and ratios) lead to greater classification accuracies. This improvement occurred because although sediment facies were distinguished mainly by differences in brightness, the various algal densities exhibited unique spectral shapes. 
This investigation also highlighted two methodological innovations not applied previously in a fluvial context. First, we demonstrated the effectiveness of a simple method for standardizing field spectra: subtracting the mean reflectance in the NIR (850 to $900 \mathrm{~nm}$ ), where water-leaving radiance is negligible even in shallow stream channels, across the spectrum. This approach accounted for extraneous sources of variability, such as drift caused by the passage of time between reference panel measurements and sun glint from the water surface, and enhanced the signal-to-noise characteristics of our reflectance data. Second, the random forest algorithm proved robust, computationally efficient, and capable of generating accurate classifications along with metrics of variable importance; this technique can be implemented using readily available software on a standard personal computer.

From a hypothesis-testing perspective, our most significant result was negative. An established approach to mapping complex benthic environments in coastal settings involves accounting for water depth and optical properties to retrieve bottom reflectance (e.g., Dierssen et al., 2003; Mobley et al., 2005; Dekker et al., 2011; Garcia et al., 2015). Based on the utility of inferred bottom reflectances for classifying coral reefs and other marine features, we hypothesized that calculating $R_{r s, B}(\lambda)$ from above-water field spectra would enhance our ability to delineate river substrates. The McNemar test results in Tables S2 and S3, however, implied that above-water field spectra provided superior classification accuracies, obviating bottom reflectance retrieval. This outcome should be reevaluated through further study, but if above-water data also prove sufficient in other cases, substrates could be classified directly from field spectra or remotely sensed data. 
A plausible explanation for the failure of bottom reflectance retrieval to improve classification accuracy could be a latent correlation between riverbed composition and water depth. If certain substrates tend to occur in deeper water while others are usually shallow, the different depths at which these bottom types are found could enhance their spectral separability by conflating the effects of depth with those of riverbed composition. Accounting for variations in depth thus might compromise discriminatory power and reduce classification accuracy, particularly for substrates with similar reflectance characteristics. In this study of the Snake River, box plots and ANOVAs indicated that various sediment facies and algal densities had different mean depths, implying that bottom reflectance retrieval might have eliminated a useful source of information — differences in reflectance driven by differences in depth - and thus made classes less spectrally distinct from one another. Although supervised classification of algal density from a hyperspectral image of Rusty Bend was more accurate for the original reflectance data than for inferred $R_{r s, B}(\lambda)$, a second, unsupervised classification produced distinct, spectrally based groupings in the bottom reflectance image. This analysis suggested that accounting for the effects of depth to isolate the reflectance of the streambed might provide additional river information.

In addition to the dependence of bottom-reflected radiance on depth and riverbed composition, several other caveats must be considered in assessing the generality of our results. For example, our field observations of bottom type were subjective, based on visual interpretation of streambed photos. Similarly, our nominal and ordinal categorizations of sediment facies and algal density, respectively, were qualitative and might not be a robust means 
of describing the bottom. The homogeneity of the Snake River's bed was another limitation of this study, as the majority of substrate photos captured a single gravel/cobble facies and relatively low algal densities; sites with greater benthic diversity would provide a more stringent test of this approach. More generally, because the observations reported herein were made on a single river over the course of one day, our findings should be interpreted as a proof of concept to justify further inquiry.

This initial study did not evaluate the true potential for spectrally based mapping of river substrates at larger scales of greater interest to geomorphologists, ecologists, and managers. All the usual caveats regarding remote sensing of rivers - such as the need for shallow, clear water, an unobstructed view of the stream, and favorable atmospheric conditions - would apply to any such effort. These considerations become even more important in the context of substrate mapping because the effects of bottom type are secondary to and confounded with those of water depth. Water column optical properties represent an additional constraint because turbidity limits the range of depths over which the bed can be detected, let alone its composition inferred. By equating the second term in Eq. (3) with the sensor's detection threshold $R_{r s, T}(\lambda)$, Dekker et al. (2005) derived an expression for the wavelength-dependent maximum detectable depth for a given substrate:

$$
z_{\text {max }}(\lambda)=\frac{1}{2 K_{d}(\lambda)} \cdot \ln \left[\frac{R_{r s, B}(\lambda)-R_{r s, D}(\lambda)}{R_{r s, T}(\lambda)-R_{r s, D}(\lambda)}\right]
$$

Beyond this depth, the riverbed cannot be distinguished from optically deep water with remote sensing reflectance $R_{r s, D}(\lambda)$. The sensor's detection limit can be characterized as the standard deviation of a homogeneous area of optically deep water (e.g., Brando et al., 2009), although this approach can 
be problematic in shallow rivers (Legleiter and Roberts, 2009).

Acknowledging these limitations, our results suggest that even though depth is the primary control on reflectance in shallow river channels, streambed composition exerts sufficient influence on the bottom-reflected radiance to enable spectrally based mapping of sediment facies and algal density. If this approach to substrate characterization proves feasible in other fluvial systems, a number of potential applications in geomorphology and ecology could emerge. For example, even a facies-level classification would provide information on spatial patterns of sediment grain size sorting that could yield insight on interactions among flow hydraulics, channel form, and patchy, localized transport processes. Similarly, knowledge of the distribution and density of algae and other forms of submerged aquatic vegetation, even at a qualitative level, could highlight relationships among algal development, flow conditions, and light and nutrient availability. The ability to infer riverbed composition from field spectra and/or image data thus represents another way in which remote sensing might advance our understanding of fluvial systems.

To realize this potential, however, further research will be required. For example, future studies might attempt to disentangle the effects of depth and bottom reflectance by building upon the work of Gilvear et al. (2007) and conducting experiments in which data are collected from the same type of substrate across a range of depths. This analysis also would constrain the maximum detectable depth for specific bottom types. Similarly, additional, more direct observations of the reflectance characteristics of various bed materials are needed. Although we have recorded field spectra within the water just above the bed, these measurements did not provide reliable information 
on bottom reflectance because they were affected by several other factors. For example, even for measurements made near the bed, the small amount of water between the sensor and substrate still must be accounted for. In addition, keeping the fore-optic a consistent distance above an irregular gravel bed has proven difficult, as has placing the white reference panel to collect data in reflectance mode, and disrupting the water surface during data collection is inevitable. An alternative strategy that would avoid these problems would involve obtaining samples of the bed materials of interest, removing them from the channel, and measuring their reflectance on a raft or on the bank where the sensor and target could be above water. O'Neill et al. (2011) used this approach in a study of coastal eelgrass, but extracting pieces of the bed and keeping them intact during measurement would be challenging even in small rivers. If such data could be acquired, however, the resulting spectral library would enable radiative transfer modeling and spectrum-matching techniques developed by coastal researchers (e.g., Mobley et al., 2005) to be applied to riverbed mapping.

\section{Conclusion}

Remote sensing methods have become an established means of characterizing rivers across a range of scales. Whereas earlier studies focused on retrieving water depth from passive optical image data, this investigation used field spectra and a hyperspectral image to evaluate the potential for spectrally based mapping of riverbed composition. We also introduced an algorithm, adapted from the coastal research community, for inferring bottom reflectance that accounts for the effects of depth and water column 
attenuation. Referring back to the research questions posed in section 1 , we can summarize our primary conclusions:

- Field spectra from the Snake River indicate that various sediment facies (including sand, gravel mixtures, and cobble) can be distinguished from one another on the basis of their reflectance characteristics.

- Similarly, spectral information can be used to differentiate between varying degrees of algal development.

- Distinctions among sediment facies and algal densities can be made based on field spectra collected from above the water surface.

- Retrieving bottom reflectance did not enhance these distinctions and thus failed to facilitate substrate mapping.

- A combination of reflectance magnitudes at key wavelengths and indices of spectral shape was the most informative set of predictor variables for classifying bottom type.

- Multispectral satellites and hyperspectral imaging systems provide sufficient spectral resolution to support streambed mapping and a larger number of narrower bands did not improve classification accuracy.

Further, more systematic study — involving field data collection from a broader range of fluvial environments as well as radiative transfer modeling is needed to explore the potential for remote sensing of riverbed composition.

\section{Acknowledgements}

This study was funded by the Office of Naval Research (N000141010873 and N000141210737) and a grant from the National Center for Airborne Laser Mapping, funded by the National Science Foundation Division of Earth Sci- 
ences Instrumentation and Facilities Program (EAR1339015). The National Park Service granted permission to collect field measurements and conduct remote sensing flights within Grand Teton National Park. The University of Wyoming National Park Service Research Center provided logistical support. Chip Rawlins and Annie Toth assisted with field data collection. David Gilvear, Paul Grams, Keith Lucey, and an anonymous reviewer provided useful reviews. Any use of trade, firm, or product names is for descriptive purposes only and does not imply endorsement by the U.S. Government.

\section{References}

Andrefouet, S., Muller-Karger, F. E., Hochberg, E. J., Hu, C. M., Carder, K. L., 2001. Change detection in shallow coral reef environments using Landsat 7 ETM+ data. Remote Sensing of Environment 78 (1-2), 150162.

Becker, B. L., Lusch, D. P., Qi, J., 2005. Identifying optimal spectral bands from in situ measurements of Great Lakes coastal wetlands using secondderivative analysis. Remote Sensing of Environment 97 (2), 238-248.

Biggs, B. J. F., Goring, D. G., Nikora, V. I., 1998. Subsidy and stress responses of stream periphyton to gradients in water velocity as a function of community growth form. Journal of Phycology 34 (4), 598-607.

Brando, V. E., Anstee, J. M., Wettle, M., Dekker, A. G., Phinn, S. R., Roelfsema, C., 2009. A physics based retrieval and quality assessment of bathymetry from suboptimal hyperspectral data. Remote Sensing of Environment 113 (4), 755-770. 
Breiman, L., 2001. Random forests. Machine Learning 45 (1), 5-32.

Buffington, J. M., Montgomery, D. R., 1999. A procedure for classifying textural facies in gravel-bed rivers. Water Resources Research 35 (6), 19031914.

Buscombe, D., 2013. Transferable wavelet method for grain-size distribution from images of sediment surfaces and thin sections, and other natural granular patterns. Sedimentology 60 (7), 1709-1732.

Buscombe, D., Grams, P. E., Kaplinski, M. A., 2014. Characterizing riverbed sediment using high-frequency acoustics: 2. Scattering signatures of Colorado River bed sediment in Marble and Grand Canyons. Journal of Geophysical Research: Earth Surface 119 (12), 2014JF003191.

Carbonneau, P. E., Lane, S. N., Bergeron, N. E., 2004. Catchment-scale mapping of surface grain size in gravel bed rivers using airborne digital imagery. Water Resources Research 40 (W07202), doi:10.1029/2003WR002759.

Carbonneau, P., Fonstad, M. A., Marcus, W. A., Dugdale, S. J., 2011. Making riverscapes real. Geomorphology 137 (1), 74-86.

Cattaneo, A., Kerimian, T., Roberge, M., Marty, J., 1997. Periphyton distribution and abundance on substrata of different size along a gradient of stream trophy. Hydrobiologia 354, 101-110.

Choudhury, M. I., Yang, X., Hansson, L. A., 2015. Stream flow velocity alters submerged macrophyte morphology and cascading interactions among associated invertebrate and periphyton assemblages. Aquatic Botany 120, $333-337$. 
Cutler, D. R., Edwards, T. C., Beard, K. H., Cutler, A., Hess, K. T., Gibson, J., Lawler, J. J., 2007. Random forests for classifications in ecology. Ecology 88 (11), 2783-2792.

Dekker, A. G., Brando, V. E., Anstee, J. M., 2005. Retrospective seagrass change detection in a shallow coastal tidal Australian lake. Remote Sensing of Environment 97 (4), 415-433.

Dekker, A. G., Phinn, S. R., Anstee, J., Bissett, P., Brando, V. E., Casey, B., Fearns, P., Hedley, J., Klonowski, W., Lee, Z. P., Lynch, M., Lyons, M., Mobley, C., Roelfsema, C., 2011. Intercomparison of shallow water bathymetry, hydro-optics, and benthos mapping techniques in Australian and Caribbean coastal environments. Limnology and Oceanography-Methods 9, 396-425.

Dierssen, H. M., Zimmerman, R. C., Leathers, R. A., Downes, T. V., Davis, C. O., 2003. Ocean color remote sensing of seagrass and bathymetry in the Bahamas Banks by high-resolution airborne imagery. Limnology and Oceanography 48 (1), 444-455.

Dugdale, S. J., Carbonneau, P. E., Campbell, D., 2010. Aerial photosieving of exposed gravel bars for the rapid calibration of airborne grain size maps. Earth Surface Processes and Landforms 35 (6), 627-639.

Dugdale, S. J., Bergeron, N. E., St-Hilaire, A., 2015. Spatial distribution of thermal refuges analysed in relation to riverscape hydromorphology using airborne thermal infrared imagery. Remote Sensing of Environment 160, $43-55$. 
Erwin, S. O., Schmidt, J. C., Nelson, N. C., 2011. Downstream effects of impounding a natural lake: the Snake River downstream from Jackson Lake Dam, Wyoming, USA. Earth Surface Processes and Landforms 36 (11), $1421-1434$.

Fearns, P. R. C., Klonowski, W., Babcock, R. C., England, P., Phillips, J., 2011. Shallow water substrate mapping using hyperspectral remote sensing. Continental Shelf Research 31 (12), 1249-1259.

Flynn, K., Chapra, S., 2014. Remote sensing of submerged aquatic vegetation in a shallow non-turbid river using an unmanned aerial vehicle. Remote Sensing 6 (12), 12815-12836.

Gao, J., 2009. Bathymetric mapping by means of remote sensing: methods, accuracy and limitations. Progress in Physical Geography 33 (1), 103-116.

Garcia, R., Hedley, J., Tin, H., Fearns, P., 2015. A Method to Analyze the Potential of Optical Remote Sensing for Benthic Habitat Mapping. Remote Sensing 7 (10), 13157.

Giller, P. S., Malmqvist, B., 1998. The Biology of Streams and Rivers. Oxford University Press, New York.

Gilvear, D., Hunter, P., Higgins, T., 2007. An experimental approach to the measurement of the effects of water depth and substrate on optical and near infra-red reflectance: a field-based assessment of the feasibility of mapping submerged instream habitat. International Journal of Remote Sensing 28 (10), $2241-2256$. 
Hedley, J. D., Harborne, A. R., Mumby, P. J., 2005. Simple and robust removal of sun glint for mapping shallow-water benthos. International Journal of Remote Sensing 26 (10), 2107 - 2112.

Hochberg, E. J., Atkinson, M. J., Andrefouet, S., 2003. Spectral reflectance of coral reef bottom-types worldwide and implications for coral reef remote sensing. Remote Sensing of Environment 85 (2), 159-173.

Hoyle, G. M., Holderman, C., Anders, P. J., Shafii, B., Ashley, K. I., 2014. Water quality, chlorophyll, and periphyton responses to nutrient addition in the Kootenai River, Idaho. Freshwater Science 33 (4), 1024-1029.

Hugue, F., Lapointe, M., Eaton, B. C., Lepoutre, A., 2016. Satellite-based remote sensing of running water habitats at large riverscape scales: Tools to analyze habitat heterogeneity for river ecosystem management. Geomorphology 253, 353-369.

Kaufman, Y. J., Remer, L. A., 1994. Detection of forests using mid-IR reflectance: an application for aerosol studies. Geoscience and Remote Sensing, IEEE Transactions on 32 (3), 672-683.

Kay, S., Hedley, J., Lavender, S., 2009. Sun glint correction of high and low spatial resolution images of aquatic scenes: A review of methods for visible and near-infrared wavelengths. Remote Sensing 1 (4), 697-730.

Kinzel, P. J., Legleiter, C. J., Nelson, J. M., 2013. Mapping river bathymetry with a small footprint green LiDAR: Applications and challenges. Journal of the American Water Resources Association 49 (1), 183-204. 
Lancaster, H., 1961. Significance tests in discrete distributions. Journal of the American Statistical Association 56 (294), 223-234.

Lawrence, R. L., Wood, S. D., Sheley, R. L., 2006. Mapping invasive plants using hyperspectral imagery and Breiman Cutler classifications (randomForest). Remote Sensing of Environment 100 (3), 356-362.

Lee, B. S., McGwire, K. C., Fritsen, C. H., 1999. Identification and quantification of aquatic vegetation with hyperspectral remote sensing in western Nevada rivers, USA. International Journal of Remote Sensing 32 (24), 9093-9117.

Lee, Z., Carder, K. L., Arnone, R. A., 2002. Deriving inherent optical properties from water color: A multiband quasi-analytical algorithm for optically deep waters. Applied Optics 41 (27), 5755-5772.

Legleiter, C. J., 2013. Mapping river depth from publicly available aerial images. River Research and Applications 29 (6), 760-780.

Legleiter, C. J., 2015. Calibrating remotely sensed river bathymetry in the absence of field measurements: Flow REsistance Equation-Based Imaging of River Depths (FREEBIRD). Water Resources Research 51 (4), 28652884.

Legleiter, C. J., Overstreet, B. T., 2012. Mapping gravel bed river bathymetry from space. Journal of Geophysical Research - Earth Surface 117 (F04024), doi: $10.1029 / 2012 j f 002539$. 
Legleiter, C. J., Roberts, D. A., 2009. A forward image model for passive optical remote sensing of river bathymetry. Remote Sensing of Environment 113 (5), 1025-1045.

Legleiter, C. J., Roberts, D. A., Lawrence, R. L., 2009. Spectrally based remote sensing of river bathymetry. Earth Surface Processes and Landforms 34 (8), 1039-1059.

Legleiter, C. J., Overstreet, B. T., Glennie, C. L., Pan, Z., Fernandez-Diaz, J. C., Singhania, A., 2016. Evaluating the capabilities of the CASI hyperspectral imaging system and Aquarius bathymetric LiDAR for measuring channel morphology in two distinct river environments. Earth Surface Processes and Landforms 41 (3), 344-363.

Lisle, T. E., Nelson, J. M., Pitlick, J., Madej, M. A., Barkett, B. L., 2000. Variability of bed mobility in natural, gravel-bed channels and adjustments to sediment load at local and reach scales. Water Resources Research $36(12), 3743-3755$.

Lloyd, S. P., 1982. Least Squares Quantization in PCM. IEEE Transactions on Information Theory 28, 29-137.

Lyon, J. G., Lunetta, R. S., Williams, D. C., 1992. Airborne multispectral scanner data for evaluating bottom sediment types and water depths of the St. Marys River, Michigan. Photogrammetric Engeineering and Remote Sensing 58 (7), 951-956.

Marcus, W. A., Fonstad, M. A., 2008. Optical remote mapping of rivers at 
sub-meter resolutions and watershed extents. Earth Surface Processes and Landforms 33 (1), 4-24.

Marcus, W. A., Fonstad, M. A., 2010. Remote sensing of rivers: the emergence of a subdiscipline in the river sciences. Earth Surface Processes and Landforms 35 (15), 1867-1872.

Marcus, W. A., Fonstad, M. A., Legleiter, C. J., 2012. Management applications of optical remote sensing in the active river channel. In: Carbonneau, P. E., Pigay, H. (Eds.), Fluvial Remote Sensing for Science and Management. Wiley-Blackwell, Chichester, UK, pp. 19-41.

Maritorena, S., Morel, A., Gentili, B., 1994. Diffuse-reflectance of oceanic shallow waters - Influence of water depth and bottom albedo. Limnology and Oceanography 39 (7), 1689-1703.

Marston, R. A., Mills, J. D., Wrazien, D. R., Bassett, B., Splinter, D. K., 2005. Effects of Jackson Lake Dam on the Snake River and its floodplain, Grand Teton National Park, Wyoming, USA. Geomorphology 71 (1-2), 79-98.

Martin, J., Eugenio, F., Marcello, J., Medina, A., 2016. Automatic sun glint removal of multispectral high-resolution Worldview-2 imagery for retrieving coastal shallow water parameters. Remote Sensing 8 (1), 37.

MathWorks, 2016. TreeBagger class. http://www.mathworks.com/help/stats/treebaggerclass.html, Accessed 1 March 2016.

McKean, J., Tonina, D., 2013. Bed stability in unconfined gravel bed mountain streams: With implications for salmon spawning viability in future 
climates. Journal of Geophysical Research: Earth Surface 118 (3), 12271240 .

McKean, J. A., Isaak, D. J., Wright, C. W., 2008. Geomorphic controls on salmon nesting patterns described by a new, narrow-beam terrestrialaquatic lidar. Frontiers in Ecology and the Environment 6 (3), 125-130.

Mendoza-Lera, C., Federlein, L. L., Knie, M., Mutz, M., 2016. The algal lift: Buoyancy-mediated sediment transport. Water Resources Research 52 (1), 108-118.

Mishra, D. R., Narumalani, S., Rundquist, D., Lawson, M., 2005. Characterizing the vertical diffuse attenuation coefficient for downwelling irradiance in coastal waters: Implications for water penetration by high resolution satellite data. ISPRS Journal of Photogrammetry and Remote Sensing $60(1), 48-64$.

Mobley, C. D., 1999. Estimation of the remote-sensing reflectance from above-surface measurements. Applied Optics 38 (36), 7442-7455.

Mobley, C. D., Sundman, L. K., 2013. Hydrolight 5.2, Ecolight 5.2 User's Guide, 1st Edition. Sequoia Scientific, Redmond, WA.

Mobley, C. D., Sundman, L. K., Davis, C. O., Bowles, J. H., Downes, T. V., Leathers, R. A., Montes, M. J., Bissett, W. P., Kohler, D. D. R., Reid, R. P., Louchard, E. M., Gleason, A., 2005. Interpretation of hyperspectral remote-sensing imagery by spectrum matching and look-up tables. Applied Optics 44 (17), 3576-3592. 
Nelson, N. C., Erwin, S. O., Schmidt, J. C., 2013. Spatial and temporal patterns in channel change on the Snake River downstream from Jackson Lake dam, Wyoming. Geomorphology 200, 132-142.

Nelson, P. A., Dietrich, W. E., Venditti, J. G., 2010. Bed topography and the development of forced bed surface patches. Journal of Geophysical Research - Earth Surface 115 (F04024), doi: 10.1029/2010jf001747.

Nelson, P. A., McDonald, R. R., Nelson, J. M., Dietrich, W. E. C. J. F., 2015. Coevolution of bed surface patchiness and channel morphology: 1 . Mechanisms of forced patch formation. Journal of Geophysical Research: Earth Surface 120 (9), 1687-1707.

O'Neill, J. D., Costa, M., Sharma, T., 2011. Remote sensing of shallow coastal benthic substrates: In situ spectra and mapping of eelgrass (Zostera marina) in the Gulf Islands National Park Reserve of Canada. Remote Sensing $3(5), 975$.

Purkis, S. J., Pasterkamp, R., 2004. Integrating in situ reef-top reflectance spectra with Landsat TM imagery to aid shallow-tropical benthic habitat mapping. Coral Reefs 23 (1), 5-20.

ReSe, 2014. ATCOR 4: Atmospheric \& Topographic Correction for wide FOV airborne optical scanner data. http://www.rese.ch/products/atcor/atcor4/.

Reshitnyk, L., Costa, M., Robinson, C., Dearden, P., 2014. Evaluation of WorldView-2 and acoustic remote sensing for mapping benthic habitats 
in temperate coastal Pacific waters. Remote Sensing of Environment 153, $7-23$.

Richards, J. A., Jia, X., 2006. Remote Sensing Digital Image Analysis: An Introduction, 4th Edition. Springer, Berlin.

Roelfsema, C., Lyons, M., Dunbabin, M., Kovacs, E. M., Phinn, S., 2015. Integrating field survey data with satellite image data to improve shallow water seagrass maps: the role of AUV and snorkeller surveys? Remote Sensing Letters 6 (2), 135-144.

Savitzky, A., Golay, M. J. E., 1964. Smoothing and differentiation of data by simplified least squares procedures. Analytical Chemistry 36 (8), 16271639.

Vahtmae, E., Kutser, T., 2013. Classifying the Baltic Sea shallow water habitats using image-based and spectral library methods. Remote Sensing 5 (5), 2451.

Verdu, J. M., Batalla, R. J., Martinez-Casasnovas, J. A., 2005. Highresolution grain-size characterisation of gravel bars using imagery analysis and geo-statistics. Geomorphology 72 (1-4), 73-93.

Visser, F., Wallis, C., Sinnott, A. M., 2014. Optical remote sensing of submerged aquatic vegetation: Opportunities for shallow clearwater streams. Limnologica - Ecology and Management of Inland Waters 43 (5), 388-398.

Winterbottom, S. J., Gilvear, D. J., 1997. Quantification of channel bed morphology in gravel-bed rivers using airborne multispectral imagery and 
1176 aerial photography. Regulated Rivers: Research \& Management 13 (6), $1177 \quad 489-499$.

1178 Zoffoli, M. L., Frouin, R., Kampel, M., 2014. Water column correction for $1179 \quad$ coral reef studies by remote sensing. Sensors 14 (9), 16881-16931. 